\title{
SOBRE LA AUTORIDAD E INTERPRETACIÓN DE LAS CONSTITUCIONES: ALGUNAS IDEAS PRELIMINARES*
}

\author{
Joseph RAZ
}

\section{Resumen:}

En este artículo se aborda no sólo la discusión en torno al tema de la autoridad de las Constituciones y la problemática de la interpretación constitucional, en donde particularmente se estudian los argumentos referentes a la autoridad de los autores de la Constitución. Además, el estudio adelanta argumentos importantes para entender el alcance y la naturaleza de las teorias que abordan los temas del constitucionalismo.

\begin{abstract}
:
The focus of this article is not only the main concerns regarding constitutionalism and specifically the problem of the authority of constitutions and the interpretation of constitutions, with a special emphasis on the authority of the authors of constitutions, the study also deals with the interesting issue of the scope and nature of theories on constitutionalism.
\end{abstract}

\footnotetext{
* Traducción de Vanessa Díaz Rodríguez y Juan Vega Gómez. Artículo publicado primero en Alexander, L. (ed.), Constitutionalism: Philosophical Foundations, Cambridge, Cambridge University Press, 1998. Derechos reservados, Cambridge University Press, 1998. Los traductores agradecen la autorización de Joseph Raz, Larry Alexander y la editorial de la Universidad de Cambridge para publicar esta traducción en la revista "Problema". Además debemos un agradecimiento a Berenice Ortega por sus comentarios, sugerencias y revisión de estilo que ayudaron enormemente para la versión final de este texto.
} 
SUMARIO: I. ¿Qué clase de Constitución? PARTE PRIMERA: La autoridad de las Constituciones. II. La autoridad de la Constitución y la autoridad de sus autores. III. El principio y práctica en la justificación. PARTE SEGUNDA. Interpretar Constituciones. IV. Interpretar la Constitución: sobre la naturaleza de las doctrinas interpretativas. V. Fidelidad e innovación. VI. Consideraciones del mérito moral de la Constitución y del papel institucional. VII. Consideraciones jurídicas y morales: el derecho y su autónomo. VIII. Coda: ¿pero es la misma Constitución?

\section{I. ¿QUUÉ CLASE DE CONSTITUCIÓN?}

Las obras sobre teoría constitucional llenan las librerías. Frecuentemente son presentadas como, y casi invariablemente son, obras sobre la práctica constitucional de un país o de otro. Debido a que ofrecen un análisis de prácticas actuales, doctrinas que tal vez justifiquen o critiquen dichas prácticas, y sugerencias para su mejoramiento, las obras son válidas, si acaso, a partir de los acuerdos politicos y constitucionales de un país o de otro, y válidas para la interpretación de la Constitución de la misma forma. Pocas obras de interpretación constitucional abordan exitosamente problemas en general; esto es, pocas ofrecen lecciones útiles en relación con la naturaleza de la interpretación constitucional como tal. En parte, esto se explica por la ambición de los autores sobre la interpretación.

Aunque sus escritos proporcionen o no un informe de las prácticas interpretativas actuales en sus países, las obras buscan casi invariablemente brindar una explicación de la manera en que la interpretación constitucional debe llevarse a cabo, una explicación del método correcto en la interpretación constitucional. También buscan presentar sus conclusiones en una forma que sea útil para abogados y jueces, y por tanto, presentarlas en una forma que disminuya las formulaciones abstractas, las cuales presuponen mucho en su interpretación y aplicación. Los autores aspi- 
ran a contribuir mediante la solución de problemas constitucionales importantes en sus países, y tal aspiración limita la importancia de sus conclusiones a una jurisdicción, o a pocas jurisdicciones similares.

Pero posiblemente las aspiraciones subyacentes no son aquello que limita la validez de la mayoría de las obras sobre interpretación constitucional. Posiblemente no exista lugar para una teoría universal sobre la materia. Después de todo, el derecho, incluyendo el derecho constitucional, puede variar de un país a otro, y de un periodo a otro, incluso en el mismo país. Inclusive, el conocimiento más básico de la Constitución y su papel en la vida y en el derecho de un país puede ser distinto en diferentes países. ¿Cómo puede haber una teoría sobre la interpretación constitucional que abarque todas esas diferencias?

Hasta cierto punto estas dudas están bien ubicadas. Un caso poderoso puede avanzarse para mostrar que una teoría sustantiva de las Constituciones y del constitucionalismo tiene una aplicación limitada. Su aplicación sólo es para algunos países y para algunas Constituciones. Una de las razones de ello radica en que la noción de "una Constitución" es utilizada algunas veces en el discurso jurídico en un sentido estricto y otras en una variedad de sentidos más amplios. En el sentido estricto, es tautológico que cada sistema jurídico posea una Constitución. En este sentido, la Constitución es simplemente la norma que establece y regula los principales órganos del gobierno, su constitución y poderes, e ipso facto, incluye el derecho que establece los principios generales sobre los que cada país es gobernado: democracia, si establece órganos democráticos de gobierno, federalismo, si establece una estructura federal, y así sucesivamente.

El sentido amplio de "Constitución" es menos claro, y probablemente existan diversos sentidos en uso en las diferentes culturas legales. Para los propósitos del presente análisis me referiré a las Constituciones como aquéllas definidas por la combinación de siete características. 
Primero, tomando su sentido estricto, la Constitución define la composición y los poderes de los principales órganos de las diferentes ramas del gobierno. Esta característica identifica a la Constitución como constitutiva de la estructura jurídica y política que es el sistema jurídico.

Segundo, tiene la intención de ser de larga duración: tiene la intención de servir como una estructura estable para las instituciones políticas y jurídicas del país, ajustada y modificada de vez en cuando, pero que básicamente mantenga la estabilidad y continuidad en la estructura politica y jurídica, y de los principios básicos que guían sus instituciones. La Constitución es estable, al menos en aspiración.

Tercero, presenta una formulación canónica. Esto generalmente significa que se encuentra consagrada en uno o en un número reducido de documentos escritos. El o los documentos comúnmente son considerados como la Constitución. La Constitución - decimos cuando nos referimos a esta característica- es escrita.

Cuarto, constituye una ley suprema. Esto significa que la ley ordinaria que contravenga la Constitución es inválida o inaplicable. La Constitución es ley suprema.

Quinto, existen procedimientos judiciales para implementar la supremacía de la Constitución, esto es, procesos judiciales por los que puede examinarse la compatibilidad de normas y de otros actos jurídicos con la Constitución y en los cuales pueden examinarse reglamentos o actos jurídicos incompatibles con ella y ser declarados inaplicables o inválidos. La Constitución es justiciable.

Sexto, mientras generalmente existen procedimientos jurídicos para reformar la Constitución, las enmiendas constitucionales son más difíciles de obtenerse que las modificaciones a la legislación ordinaria. La Constitución es rígida.

Séptimo, sus estipulaciones incluyen principios de gobierno (democracia, federalismo, derechos civiles y políticos básicos, etcétera) que generalmente tienden a expresar las creencias comunes de la población sobre la forma en que la sociedad debe ser gobernada. La Constitución sirve, podría 
decirse, no sólo como un derecho de los abogados, sino como el derecho de la gente. Sus estipulaciones principales son generalmente conocidas, y exigen un consentimiento general, y son consideradas como la ideología común (o parte de ella) que gobierna la vida pública en el país. La Constitución expresa una ideología común.

Esta caracterización de una Constitución (en sentido amplio) arroja un concepto vago. Cada una de las siete características mencionadas resulta vaga en su aplicación. Para dar un ejemplo: ¿si es una condición que un país tenga una Constitución escrita (condición 3), esto implica que no puede existir una parte "no escrita" de la Constitución, por ejemplo, una parte que sea derecho consuetudinario?, ¿y si la característica de que la Constitución debe ser escrita es compatible con la idea de que parte de la Constitución puede no estar escrita, se deduce que Gran Bretaña tiene una Constitución escrita? Recordemos que aunque algunas Constituciones (en sentido estricto) son derecho consuetudinario o common law, parte de ellas (e.g., el Bill of Rights de 1689, el Acta de la Unión entre Inglaterra y Escocia de 1706, el Acta de Comunidades Europeas de 1971) es derecho escrito. Sabemos que en el sentido relevante la Gran Bretaña no tiene una Constitución escrita. Pero esto no se deduce claramente de la caracterización dada, la cual es vaga en este punto.

Pero esta caracterización no tiene como objetivo fijar delimitaciones, sino enfocar el debate. Su propósito es enfatizar las características principales de las Constituciones, en (un) sentido amplio, características que explican porqué "algunas" Constituciones, esto es, Constituciones en sentido amplio, dan origen a cuestiones teóricas no aplicables, al menos no en el mismo grado, a otros derechos. Este ensayo considerará algunas cuestiones referentes a las Constituciones en este sentido. Algunas de las preguntas, e incluso algunas de las respuestas, se aplican a Constituciones que presentan sólo algunas de las características especificadas o las presentan sólo en alguna medida. Ciertamente, algunas de ellas son aplicables también al derecho ordinario 
(i.e., no constitucional). Pero resulta útil discutirlas en el contexto constitucional y no nos interesaremos en qué medida dichos problemas o sus soluciones aplican en otro lugar.

Tendría poco sentido estudiar en términos generales las Constituciones en sentido amplio si no juegan un papel trascendente en la vida de muchos paises. Ciertamente no todos los países tienen una Constitución en este sentido. La Gran Bretaña actualmente, y el Imperio Romano en el pasado, son dos ejemplos de países que no la tienen o no la tuvieron. La ausencia de una Constitución, en el sentido amplio, puede deberse a una serie de factores. Uno, es que el país disfrute de un nivel de consenso político tal que hace innecesaria la existencia de una Constitución. Tal consenso significa que cada persona conoce y acepta la estructura del gobierno, la distribución de los poderes entre sus órganos, y los principios generales que guian o constriñen el ejercicio de los poderes del gobierno. Éstos son, si se quiere, materia de convenciones sobre entendidas, sin mecanismos para su ejecución. Un consenso de esta naturaleza puede existir en un país pequeño con una población relativamente homogénea y estable, que goce de relativa equidad en su estatus y de una economía firme. Pero este consenso puede también existir en un país más grande, con una población diversa, marcada por una considerable estratificación social y económica, si ésta está basada en una cultura de respeto y si goza de condiciones sociales, demográficas y económicas estables.

Constituciones en el sentido amplio tienden a existir en sociedades que disfrutan de una relativa estabilidad frente a la diversidad y al cambio. Tales sociedades deben tener estabilidad y un sentido de identidad lo suficientemente común para asegurar la durabilidad y estabilidad de la Constitución misma. Pero cuando se trata de sociedades "de gran escala", con múltiples divisiones, por ejemplo, de religión, clase u origen étnico, se necesita de la seguridad de un gobierno responsable, guiado claramente por principios 
de administración, para fortalecer la estabilidad de las estructuras politicas y la autoridad de sus instituciones jurídicas. Un indicio tentador sugiere que la forma de construir una teoría de la autoridad y de la adecuada interpretación de la Constitución (en sentido amplio) es mediante la exploración de las condiciones sociales, culturales y económicas que la justifican. Seguramente esta perspectiva goza de las herramientas para entender la naturaleza y la función de la Constitución y por tanto, su autoridad e interpretación. Pero los indicios se equivocan. No hay duda de que esta investigación será valiosa. Sin embargo, no producirá los resultados deseados. Esto presupone que el derecho, y el derecho constitucional por lo menos, se desarrollan exclusivamente en respuesta a las características relativamente estables de las condiciones sociales del país en que se aplica. Como sabemos, esta perspectiva es demasiado racionalista en relación al desarrollo del derecho. Mucho de este desarrollo depende de la ambición de personajes poderosos, de la conveniencia política del momento. El fluctuante estado de ánimo de la sociedad e incluso los virajes económicos temporales pueden llevar a cambios que permanezcan en vigor después de muchos años de que las condiciones que los produjeron hayan sido olvidadas.

El asunto tampoco es distinto tratándose de Constituciones. El pensamiento de que su "estatus más alto" y de que su propensión para la longevidad las hace receptivas sólo a las condiciones sociales fundamentales y duraderas o a las tendencias sociales se encuentra equivocado. En 1995, por dar un ejemplo, las voces influyentes del Partido Británico del Trabajo propusieron una reforma constitucional como centro de su plataforma política, dado que la situación económica en el país parecía estar mejorando, lo cual beneficiaba al gobierno Conservador en las elecciones venideras. De forma similar, aunque discutible, las Cortes en Gran Bretaña no hubieran sido tan activas entre finales de la década de los ochenta y mediados de la década de los noventa en el desarrollo de nuevas doctrinas en derecho público, di- 
rigiendo una serie de fracasos humillantes para el gobierno, de no ser por el hecho de que los conservadores han estado en el poder por diecisiete años, enfrentándose con una reducida oposición parlamentaria efectiva. La política constitucional puede no ser la misma que la política parlamentaria, pero ambas no están completamente separadas. Ejemplos similares pueden encontrarse en la historia de otros países, incluso en aquéllos con una Constitución en sentido amplio. Además, en nuestro mundo contractual eterno, la adopción de las Constituciones, y la forma en que se desarrollan, usualmente obedecen más a la moda que a los principios. Determinadas formas de entender la Constitución se convierten en moda, tal vez debido al prestigio del país que las inició. Seguir la moda se convierte en lo politicamente conveniente. Más de lo que quisiéramos admitir se debe a este último factor.

Podría objetarse que ninguno de estos factores importa a la teoría constitucional, la cual es una teoría normativa y por tanto, no se encuentra afectada por meras contingencias. Ciertamente en el sentido que se abordará, la teoría constitucional es normativa. Pero eso no significa que ignore o deba ignorar las realidades básicas de la vida. Que la adopción y el desarrollo de las Constituciones sean afectadas por una variedad de factores a corto plazo no es una mera aberración en la vida de un país o de otro. Es una característica universal de la vida política de todos los países con una Constitución. La teoría constitucional debe permitirlo. La teoría que condena todas esas influencias como aberraciones que deben ser evitadas es tan remota en este mundo que resulta inútil.

Debemos regresar a este punto y discutirlo más adelante. Y mientras que la investigación principal tendrá que esperar una detallada discusión de la normatividad de la teoría constitucional, podemos comenzar haciendo una observación importante: una buena parte del desarrollo jurídico (y esto incluye el desarrollo constitucional) es autónomo. Esto significa que las tradiciones se cristalizan en prácticas que 
llevan a decisiones que desarrollan el derecho constitucional. Estas tradiciones pueden estar alimentadas por consideraciones válidas, tales como el interés por la eficiencia del gobierno, o por la dignidad de los individuos, o por la relativa autonomía de las diferentes regiones. Pero el punto crucial es que esas consideraciones no determinan el resultado de las decisiones que influyen. Esas consideraciones serán respetadas por una variedad de decisiones constitucionales. En realidad, la decisión tomada es elegida a partir de hábitos, o del respeto por las prácticas constitucionales y tradiciones de ese país.

Si eso es correcto, y si las tradiciones jurídicas autónomas de diferentes países, en mayor medida influyen justamente en determinar su desarrollo constitucional, entonces una teoria constitucional no puede estar basada en factores sociales, económicos o culturales. No debe obtenerse de situaciones ajenas. Debe permitir un papel más relevante a consideraciones jurídicas internas. Por tanto, las reflexiones sobre teoría constitucional ofrecidas aquí proceden del examen de las características abstractas centrales de una Constitución, las siete características enumeradas anteriormente y algunas de sus implicaciones. La teoría se abstrae de los posibles impactos de las condiciones sociales, dado que presupongo que diferirán de país a país. Espero, de cualquier manera, que una teoría de la Constitución brindará la estructura teórica dentro de la cual puedan ser valoradas las consecuencias de las condiciones sociales diversas.

Creo que la mayor parte de lo que se requiere decir acerca de la naturaleza de las Constituciones ha sido ya dicho. Esto no significa, por supuesto, que la temática es clara y decidida. El problema no es tanto como que la verdad es escurridiza y que no ha sido advertida por nadie, sino que una variedad de analogias sin rumbo ha contribuido a la producción de ideas equivocadas. Dedicaré gran parte de este ensayo a tratar de explicar por qué no debemos escuchar a algunas falsas sirenas. 
Podemos empezar, sin embargo, señalando uno de los principios que parece ser el terreno común de muchos enfoques de los estudios constitucionales: la teoría de la Constitución comprende dos partes, una sobre la autoridad de las Constituciones y otra sobre la forma en que las Constituciones deben ser interpretadas. La primera explica bajo qué condiciones la Constitución de un país es legítima, de esta manera, fija la condición bajo la cual los ciudadanos tienen el deber de obedecerla. Al hacer esto, esta explicación proporciona un recuento de los principios de moralidad política que sirven de base a la Constitución, principios que justifican y legitiman su cumplimiento, si es que efectivamente está justificada. La teoría de la interpretación constitucional explica la manera en que son determinados los principios de la interpretación constitucional en diferentes países. Un principio de teoría constitucional que exige ser respetado es el que sostiene que los principios de la interpretación constitucional dependen en parte de la teoría de la autoridad de la Constitución. Al determinar las condiciones para la legitimidad constitucional, la teoría de la autoridad de la Constitución contribuye a la determinación de los principios de interpretación. Desafortunadamente, este principio viable es también la fuente de muchas falsas analogías motivadas por el intento de asimilar la autoridad de la Constitución a la de otras partes del derecho.

\section{PARTE PRIMERA: LA AUTORIDAD DE LAS CONSTITUCIONES}

\section{LA AUTORIDAD DE LA CONSTITUCIÓN Y LA AUTORIDAD DE SUS AUTORES}

Resulta tentador pensar que la autoridad del derecho, de cualquier ley, deriva de la autoridad de su autor. El derecho consuetudinario es una enigmática excepción. Pero consideremos la ley promulgada, esto es, la ley cuya validez deriva del hecho de que fue realizada por una autoridad jurídica que actúa con la intención de expedir dicha ley. El ejemplo 
paradigma de este tipo de ley es la legislación. Ella es válida porque fue aprobada por un órgano autorizado por la ley para realizar esas funciones. Si por ejemplo, la validez jurídica de un reglamento es impugnada sobre la base de que el órgano que lo expidió carece de facultades para hacerlo, la contestación no va a ser, por más justificada que sea, que la regla que contiene el reglamento es legalmente vinculante porque es una regla buena, una que es susceptible de ser obedecida. Esto no significa que el mérito de las normas sea irrelevante para el razonamiento jurídico. En contextos apropiados, tales consideraciones pueden guiar la interpretación de un estatuto o reglamento cuya validez jurídica se encuentre establecida por otras justificaciones. En algunos contextos, el mérito de tener normas de cierto tipo puede incluso justificar que los tribunales las adopten $\mathrm{y}$ basen sus decisiones en ellas, incluso si esto requiere anular normas legalmente constituidas. El mérito de una norma puede deberse también a los motivos que le dan fuerza vinculante, ya sea a través de los tribunales, mediante precedente o por medio de legislación. Pero el mérito de una norma no es el tipo de consideración que puede establecer que sea legalmente vinculante.

Criticamos este punto conocido para llegar al hecho, por sí mismo obvio, de que la identidad del legislador es materia de la validez de la ley, al menos en el caso de la ley promulgada. Es plausible pensar que sólo si la identidad del legislador es la razón para la validez de la ley, podemos explicarla como característica de la ley promulgada. El hecho de que la ley fuera creada por esa persona o institución brinda, desde este punto de vista, la justificación (o al menos un nivel de justificación) para sostener como válida la regla promulgada. Esto significa que tratándose de la ley promulgada, la autoridad de la ley deriva de la autoridad de su creador.

Éste es un poderoso argumento que sostiene que la autoridad de las Constituciones deriva de la autoridad de sus creadores. El argumento no implica que no exista otra for- 
ma en que la ley pueda tener autoridad. El derecho consuetudinario muestra que hay otras maneras de establecer la autoridad de la ley. El argumento tampoco sostiene que cualquier cosa hecha con la intención de crear derecho debe, si es que es jurídicamente válido, derivar su autoridad de la autoridad de su creador. En Gran Bretaña, por mencionar un ejemplo, una regulación que contenga una regla puede ser ultra vires, pues el órgano que la adoptó no tenía facultades para crear leyes en esa materia, y aun la ley que la disposición contempla puede ser válida, puede ser el caso si se trata de una regla de derecho común con bastante arraigo. El argumento se encuentra en otra parte. A menos que la autoridad de la Constitución derive de la autoridad de sus creadores, no existe explicación que importe sobre el hecho de que haya sido creada por un órgano en lugar de otro. Pero claro que hace toda la diferencia el que la Constitución sea adoptada por aquellos que efectivamente la adoptaron, y no por otros. Es decir, queremos señalar que es válida porque así fue adoptada. Entonces, por la fuerza del argumento esbozado, ¿se sigue el que su autoridad deriva de la autoridad de aquellos que la crearon?

Como sucede frecuentemente en estos casos la respuesta corta es sí y no. Para explicar esto, es necesaria una respuesta larga. Pero primero debemos eliminar una respuesta falsa que tenemos a la vuelta de la esquina. Este interés no se encuentra en la misma respuesta falsa, sino en que nos lleva a enfrentarnos con el aspecto perenne de las relaciones entre el derecho y moralidad. Puede sostenerse que la autoridad de las Constituciones no puede derivar de aquélla de sus creadores, ya que sus creadores, en el nacimiento de sus Estados, no podian tener autoridad. Toda autoridad deriva de la Constitución que ellos mismos hicieron sin previa autoridad para hacerla. 


\section{La naturaleza de la autoridad de los creadores de una Constitución originaria}

Para tomarlo seriamente, este argumento debe ser reducido a las pocas Constituciones que pueden llamarse "originarias". La mayoría de las Constituciones no son así. Éstas son creadas por autoridades jurídicas legitimas como parte de un proceso de reforma jurídica. Incluso las Constituciones que acompañan el nacimiento de un nuevo país independiente a menudo son hechas con base en la autoridad jurídica conferida a sus creadores por el orden jurídico previamente en vigor en los mismos, generalmente un régimen colonial. Esta es la forma en que la mayoría de los países de la Comunidad Británica adquirieron su independencia. Pero ¿no es el argumento convincente respecto a aquellas Constituciones a las que se aplica?, no lo es.

El argumento supone que sólo aquellos a quienes la autoridad ha sido conferida por una ley preexistente pueden tener autoridad legítima. Esto no es, ni puede ser el caso. La autoridad jurídica es en sí misma una forma de autoridad moral pretendida. ${ }^{1}$ El punto se pierde de vista a veces, pero las estructuras jurídicas transmiten la autoridad de crear la ley de un órgano a otro. Estamos familiarizados con el hecho de que el derecho es una estructura de la autoridad, en la cual cada autoridad jurídica obtiene su poder de leyes creadas por otra. Nos basamos en la autoridad de unas para justificar la autoridad de otra. Sólo excepcionalmente apelamos a las razones morales para justificar la pretensión de autoridad jurídica. Esto proporciona un discurso de que la autoridad jurídica es supuestamente autónoma, técnica y, al fin y al cabo, discurso jurídico. En cierta forma lo es. Si la Constitución y otras leyes que establecen las autoridades jurídicas están moralmente justificadas, también lo están las autoridades que se crean y por lo tanto

1 Véase, para una discusión amplia, Raz, Joseph, The Morality of Freedom, Oxford University Press, 1986, Parte 1, y Raz, Joseph, Ethics in the Public Domain, edición revisada, Oxford, Oxford University Press, 1995, Ensayos 9 y 10. 
las leyes creadas por tales autoridades son moralmente obligatorias.

Esto significa que una vez que la justificación moral de dichas normas jurídicas últimas (esto es, aquéllas cuya validez jurídica no se presupone de ninguna otra ley) es establecida, o supuesta; la justificación moral del resto del derecho - hasta cierto punto- se determina por una argumentación jurídica técnica (esto es sólo hasta cierto punto porque, como fue advertido, la interpretación del derecho puede involucrar otras consideraciones morales o no legales). Puesto que una parte del tiempo el argumento jurídico se dirige a los funcionarios legales que aceptan la validez moral de las leyes últimas, y gran parte de los argumentos jurídicos explican, a clientes o abogados o a cualquier persona, cuál es la posición en el derecho -en el supuesto de que éste sea moralmente legítimo- en relación con un asunto u otro, gran parte del argumento jurídico es técnicamente jurídico.

Nada de esto niega el hecho de que el derecho pretende ser moralmente vinculante y que en general sólo la gente que acepta tal pretensión, la gente que acepta por lo menos que es moralmente permisible aplicar el derecho (para establecer impuestos, para determinar sus derechos de propiedad, o su derecho en o al empleo, o encarcelarlos, etcétera), se basan en las autoridades que crean y aplican el derecho. Una teoría del derecho es, por tanto, y entre otras cosas, una teoría de las condiciones, si es el caso, bajo las cuales el derecho es moralmente legitimo y de las consecuencias que derivan de la presunción de que es moralmente legítimo. Esta es también la naturaleza de nuestra investigación sobre la autoridad de la Constitución. Si la Constitución no es una Constitución originaria, si ha sido creada por un órgano en el cual alguna otra ley (tal vez una Constitución anterior) confirió el poder de promulgar una Constitución, entonces ésta puede encontrarse dotada de legitimidad moral si es que la ley que la autorizó es moralmente legítima. Pero si se trata de una Constitución originaria, entonces la cuestión 
sobre su legitimidad moral no puede volcarse a la legitimidad de cualquier otra ley. Debe dirigirse directamente hacia un argumento moral.

Se deduce entonces que no es válido el argumento de que una Constitución originaria no puede obtener su autoridad de la autoridad de sus creadores porque ellos no tienen tal autoridad. Es cierto que los creadores de una Constitución no tuvieron autoridad conferida a ellos por otras leyes. Pero esto no implica que ellos no hayan tenido autoridad, ni que la autoridad de la Constitución no pueda basarse en su autoridad. Puede ser que ellos gocen de autoridad moral y ésta puede ser la razón de la autoridad de la Constitución.

Se podría replicar que aunque mis observaciones son verdaderas pierden el punto que intentaban refutar. Tal argumento, puede decirse, versa sobre la autoridad juridica de las Constituciones originarias y no sobre su autoridad moral. En cierto sentido es cierto que sus creadores no tenian autoridad jurídica (es engañoso señalar este punto en esta forma, pero las consideraciones técnicas no exigen que nos detengamos en este punto). ${ }^{2}$ La cuestión importante es que nuestro interés en la autoridad jurídica radica en cómo se establece la autoridad moral del derecho o de parte del mismo. Estamos interesados en la autoridad del derecho, si existe, a fin de establecer si tenemos la obligación de obedecerlo. ${ }^{3}$ Más aún, el fundamento de la autoridad del derecho ayuda a determinar cómo debe ser interpretado. Los jueces, tal vez más que nadie, siguen el derecho porque creen que moralmente están obligados a ello. No puede haber otra manera en la que puedan justificar ${ }^{4}$ el encarcelamiento de

2 Discuto algunos de ellos en The Concept of a Legal System, 2a. ed., Oxford, Oxford University Press, 1980, pp. 29-32.

3 La pregunta sobre la autoridad del derecho no agota el tema de la obligación política, sin embargo, es gran parte del mismo.

4 Posiblemente, algunos ocupan un cargo judicial por razones de ventaja personal incluso cuando consideran que hacerlo está moralmente mal. En algunos regímenes opresivos podemos imaginar a los jueces y a otros funcionarios cometiendo inmoralidades por temor a sus vidas o por la vida de sus familias. En tales circunstancias, actuar así puede ser excusable moralmente. Pero lo anterior se 
la gente, la intervención en su propiedad, trabajos, relaciones de familia, etcétera, decisiones que son rutina diaria de la vida judicial.

Vale la pena reiterar que nada de esto implica que no exista cabida para un razonamiento jurídico más enfocado a la cuestión de si una institución cumple con las condiciones puramente jurídicas para poseer autoridad. Mi postura es que dicho estudio es de interés debido a que encaja en una investigación más amplia sobre la legitimidad moral del poder de esa institución. Ni tampoco sostengo que en ninguna serie de razonamientos acerca de la autoridad juridica habrá un lugar en el que las consideraciones morales que afecten la legitimidad se verán confrontadas directa o explicitamente. Muy a menudo éstas se dan por sentado. Ni es mi postura, por supuesto, de que cuando las condiciones jurídicas de legitimidad son cumplidas también lo son las condiciones morales.

\section{El argumento derivado de la regla de reconocimiento}

Este puede ser un lugar apropiado para eliminar otro argumento equivocado sobre la independencia de la autoridad de la Constitución de aquélla de sus creadores. Algunos teóricos, que libremente siguen la teoría jurídica de H. L. A. Hart, consideran que la Constitución de un país es su regla de reconocimiento, tal y como Hart utiliza el término. ${ }^{5}$ Dado que la regla de reconocimiento existe como práctica de los funcionarios jurídicos, es, por decirlo de alguna forma, una norma viva, una norma sustentada por actitudes $y$ conductas actuales, y no por lo que ocurría en el momento en que se originó. Por consiguiente, dado que la Constitución es la regla de reconocimiento, la autoridad de la Constitución deriva de la

trata de una excepción, y haré caso omiso de tales situaciones en la presente discusión.

5 Véase Hart, H. L. A., The Concept of Law, edición revisada, Oxford, Oxford University Press, 1961, edición revisada, 1994. 
práctica actual de los funcionarios, y no de la autoridad de sus creadores.

Este argumento se refuta fácilmente. Por un lado, su conclusión puede virarse y ser usada como base para rechazar su premisa central: si la Constitución es la regla de reconocimiento, entonces su autoridad no deriva de la autoridad de sus creadores; dado que su autoridad proviene de la autoridad de sus autores, se deduce entonces que la Constitución no es la regla de reconocimiento. No hay razón para preferir este argumento o la versión inversa del mismo. Esto nos deja en la misma situación. Afortunadamente, existen múltiples razones independientes que establecen que las Constituciones no son las reglas de reconocimiento de sus países. Ninguna Constitución lo puede ser, si se le considera en el sentido amplio que ha sido utilizado aqui. Por ejemplo, muchas de las Constituciones pueden ser reformadas e incluso derogadas y sustituidas por otras, conforme a los procedimientos que ellas mismas consagran. Esto significa que pueden ser reformadas o derogadas mediante decreto. La regla de reconocimiento no puede ser derogada o reformada por medio de decreto. Sólo puede cambiar si la práctica cambia. El derecho consuetudinario puede ser derogado y sustituido por un estatuto. No hay nada en la naturaleza de la costumbre que la prevenga de ser cambiada por la legislación. Pero una vez que ocurre, el derecho ya no es costumbre. Es ley. La regla de reconocimiento, por otro lado, no puede dar cabida a un derecho legislado; ésta es y siempre será consuetudinaria.

No sólo es un error identificar a las Constituciones con las reglas de reconocimiento, sino que además las reglas de reconocimiento no juegan el papel legitimador que las Constituciones pueden representar. ${ }^{6}$ Las reglas de reconocimientos no son como el resto del derecho. Es la práctica - esto es, el hecho- que los tribunales y otras instituciones

6 El panorama expresado en este párrafo y en el siguiente son una variante de la interpretación de Hart sobre la regla de reconocimiento, como lo explica en el post-scriptum a la edición revisada de The Concept of Law. 
jurídicas reconozcan la validez, legitimación, del derecho, y están dispuestos a seguirla y aplicarla en relación con otros. Como tal resulta ser distinta de otras leyes, incluyendo a las normas jurídicas consuetudinarias. Finalmente es el punto (uno de los puntos) en el que - metafóricamente hablandoel derecho termina y la moral comienza. Es el hecho que nos permite separar los actos jurídicos de los morales. Si la regla de reconocimiento existe - esto es, si la práctica adecuada de reconocimiento es seguida por los tribunales- entonces el derecho existe. Pero sólo si ellos están en lo correcto al conducirse de tal forma, el derecho viene a estar dotado de legitimidad y resulta vinculante moralmente hablando.

Pongámoslo en otros términos: debido a que podemos identificar el hecho social del reconocimiento judicial del derecho por los tribunales, podemos establecer que hay una ley en cierto país y establecer su contenido incluso si se trata de un sistema jurídico malo e ilegítimo moralmente hablando. La regla de reconocimiento, como hecho social, nos permite identificar el derecho sin recurrir a la moralidad. Pero esto es todo lo que hace. No puede ser considerada como regla convencional - esto es, no podemos suponer que sea una verdad necesaria el que cuando un juez siga la práctica de, digamos, aplicar decretos aprobados como obligatorios por la reina en el Parlamento, lo haga asi porque todos los tribunales lo hacen o porque todos se sientan obligados a hacerlo, aunque lo hagan-. Tal vez lo hagan porque las leyes del Parlamento disfrutan de legitimidad democrática o por alguna otra razón. La regla de reconocimiento constituye una práctica normativa, pero no una práctica convencional.

\section{El argumento del consentimiento}

Algunas personas piensan que la única manera en que otros pueden tener poder sobre los demás es a través del 
consentimiento de los demás. ${ }^{7}$ Dado que la Constitución es la fuente de la autoridad jurídica en el Estado, su propia autoridad debe surgir del consentimiento del gobernado. Si el consentimiento es la fuente de toda autoridad, entonces este consentimiento debe ser el consentimiento de los vivos, el consentimiento de las personas sujetas al derecho en el momento específico. Quienes piensan que el consentimiento es el fundamento de la autoridad no pueden tolerar la suposición de que la generación actual esté sujeta al derecho porque éste goza del consentimiento de la población que vivió hace 200 años. Por tanto, incluso si una Constitución fue adoptada por un referéndum, es válida no por el proceso por medio del cual fue adoptada originalmente, sino porque así lo exige el consentimiento de la sociedad en un momento determinado.

Algunas variantes de este argumento lo modifican para dar lugar a dos objeciones. Primero, el hecho de que algunas personas puedan negar su consentimiento por capricho de una manera totalmente arbitraria o irracional. Cuando esto ocurre, aquellos que niegan su consentimiento no estarán sujetos al derecho del Estado. Ellos pueden violar la ley con impunidad; sin embargo, parece inverosímil que sea así de fácil escapar de la autoridad del derecho, que la gente pueda escapar de su autoridad a voluntad. Segundo, mucha gente nunca ha sido llamada para dar su consentimiento a la Constitución. Muchos pueden no haber dado su consentimiento porque simplemente nunca se les ocurrió que pudieran darlo. De nuevo, parece inverosimil que ellos estarán exentos de la autoridad de la ley. Ambas objeciones pueden ser delimitadas si alguien sostiene que el consentimiento que otorga autoridad a la Constitución no es necesariamente el consentimiento actual del gobernado. Más bien, al menos respecto de quienes no dieron su consenti-

7 Otras variantes del argumento lo relacionan con la democracia más que con el consentimiento. Las consideraciones adelantadas en contra de la versión considerada en el texto tienen que ser adaptadas para aplicarse a otras variantes del argumento. 
miento, es el hecho de que ellos habrian consentido - siendo gente razonable y racional, pero no necesariamente gente moralmente ejemplar- si ellos hubieran sido invitados a hacerlo. Estas variantes apelan a la autoridad como producto del consentimiento hipotético del gobernado.

Éste no es lugar adecuado para llevar a cabo un estudio extenso sobre la debilidad de las explicaciones consensuadas de la autoridad. ${ }^{8}$ Basta decir que mientras que en relación a lo mencionado, las explicaciones basadas en el consentimiento hipotético son más fuertes que las explicaciones basadas en el consentimiento simple, en otros aspectos es más débil la explicación. Existe algo de fuerza normativa en el hecho de que uno dé su consentimiento libre e informa$\mathrm{do}^{9}$ a un acuerdo que lo afecta a uno, fuerza que el consentimiento hipotético no tiene. El consentimiento, acertado o uno erróneo, expresa la voluntad del agente en relación con la conducta de su propia vida. Cualquier desastre que derive de este consentimiento es, en parte al menos, su propio problema. Dado que su vida es suya, resulta relevante si ésta se encuentra bajo su control o no, y el consentimiento demuestra que sí lo está. Por lo que incluso si el consentimiento real es fuente de autoridad, esto está lejos de demostrar que el consentimiento hipotético también lo es. No conozco algún argumento que pruebe que sí lo sea. ${ }^{10}$

En cualquier caso, esta relevancia del consentimiento no es del tipo que pueda establecer la legitimidad de alguna autoridad. No siendo pertinente discutir de lleno este caso,

8 Las he tratado en "Government by Consent", Ethics in the Public Domain, p. 355 .

9 No queremos decir que ese consentimiento es racional dada la información, sino que -considerado a la luz de la información generalmente disponible en el momento- la información conocida por el agente le presentó una imagen aproximada verdadera de las características (no evaluativas) de la situación, en tanto que fueron relevantes para su decisión.

10 Esto no implica negar que los argumentos que no se encuentran basados en el consentimiento no pueden ser presentados como relacionados con el consentimiento hipotético: supongamos que se tiene una obligación derivada de cualquier fuente de reconocer la autoridad de ciertos gobiernos. Se sigue que si usted conoce sus obligaciones consentiría que tiene la obligación de reconocer la autoridad de tales gobiernos. 
pero nos permitimos dar una analogía: supongamos que consiento a una pelea con un oponente superior en cuanto a fuerza y habilidades, estoy enojado con él y simplemente perdí la cabeza por el deseo de pelear contra él. Que yo consintiera es relevante para lo que diré después cuando estén curando mis heridas, esto importa para el tipo de reclamos que puedo hacer (puedo decir a mis amigos "¿por qué no me detuvieron?", pero no puedo decir a mi enemigo "¿por qué peleaste contra mí?”). Esto también afecta cualquier juicio razonable sobre mi carácter. Pero eso no necesariamente significa que mi enemigo estuviera en lo correcto al pelear conmigo. Él debió haber sabido que el pelear es inmoral y que mi consentimiento no lo hace de otra manera. Él debió haber sabido que la pelea no era justa, dada su superioridad (él no estaba peleando en defensa propia; era una pelea concertada). Tal vez usted pueda no coincidir con los juicios aquí vertidos, pero, debe estar de acuerdo en que si son ciertos, entonces mi consentimiento no hizo que la acción de mi enemigo fuera correcta. El caso del gobierno legítimo es similar: mi consentimiento puede excluirme de hacer ciertas quejas y puede ser materia para juzgar mi carácter, pero no puede dotar al gobierno con un derecho para gobernar si no lo tiene - a menos que el consentimiento sea relevante para su derecho en una forma que es diferente a la comentada anteriormente-. Asumiremos a continuación que dicho aspecto del consentimiento no es relevante para nuestro problema.

Es plausible suponer que cualquiera que sea el mérito que haya en las explicaciones del consentimiento hipotético, éste deriva del hecho de que el tipo de consentimiento hipotético que implican capta lo relevante de las explicaciones sobre el consentimiento real, por ejemplo, que represente la verdadera voluntad del gobernado. En esa medida, dichas explicaciones sufren de algunas limitaciones del consentimiento real -que son aquellas que no sólo afectan la forma del consentimiento, sino su fundamento subyacente-. Un aspecto importante del consentimiento, como ac- 
ción humana, es que se da por una razón —esto es, una razón que el agente considera como buena razón-, a la luz de todas las consideraciones, incluso las consideraciones morales que aplican al caso. Las razones que los agentes creen que pueden no ser buenas razones o no estar adecuadas a la tarea, y los agentes pueden incluso saberlo y dar su consentimiento debido a la debilidad de su voluntad. Como sea, no conozco alguna explicación basada en el consentimiento que no suponga que las razones para darlo sean convincentes y adecuadas. Efectivamente, sería imposible explicar a la autoridad con base en un consentimiento que está equivocado y mal fundado - de nuevo, un punto que no puede establecerse aquí-. Entonces, el consentimiento es dado por la creencia verdadera de que es el motivo adecuado para reconocer la autoridad de las instituciones o principios en cuestión. La duda es si estas consideraciones no son suficientes para establecer la autoridad de aquellos órganos o principios, independientemente del consentimiento.

Obviamente, en muchos casos el consentimiento se requiere para que tengamos una obligación. Pero típicamente estos son casos en los que la sabiduría del consentimiento no está puesta en duda (e.g., con pocas excepciones, una promesa es obligatoria aunque las razones para hacerla sean o no buenas razones). Es igualmente claro que no todas las obligaciones surgen del consentimiento o de las tareas que se llevarán a cabo (e.g., la obligación de mantener una promesa no depende de nuestro consentimiento). Ni todas las obligaciones de aceptar la voluntad de otros deriva del consentimiento (e.g., tenemos dentro de ciertos límites la obligación de aceptar la voluntad de nuestros padres, lo que - al menos en las condiciones que prevalecen en algunas sociedades - se extiende más allá de la niñez y se aplica a las relaciones entre adultos y sus padres). Así que surge la siguiente pregunta: si el consentimiento a la autoridad es efectivo sólo cuando está basado en razones adecuadas 
para reconocer la autoridad, ¿por qué esas razones no son suficientes por si mismas para establecer tal autoridad?

Esta es una pregunta seria, no retórica. Podemos imaginarnos respuestas que podrian mostrarnos que en ciertos asuntos nadie puede tener autoridad sobre otro excepto con el consentimiento de la persona. Éste puede ser el caso de los asuntos referentes a lo que llamamos "áreas de la vida privada". Lo que es más dificil de imaginar es que ninguna autoridad política puede ser legítima sin consentimiento - es decir, que no existe un área sobre la cual la autoridad pueda tener poder legitimo independientemente del consentimiento-. Muchas áreas propias de las acciones de gobierno (determinar la contribución de los individuos para mantener los servicios públicos o asegurar que los que realizaron injurias contra otros sean compensados por el daño causado cuando así lo requiera la equidad o la justicia) son asuntos que establecen esquemas para facilitar la conformidad con los preceptos de justicia y moralidad, y ésos son asuntos típicos en los que hay obligaciones que no dependen de la voluntad.

Suponiendo que en muchas áreas la autoridad no depende del consentimiento, entonces es más viable que en estos asuntos al menos, el consentimiento no sea en absoluto una forma de establecer la autoridad. ${ }^{11}$ Lo anterior dado que parece razonable suponer que en relación con tales asuntos, las únicas razones que justifican el consentimiento a la autoridad también justifican la autoridad sin consentimiento.

Si el esbozo del argumento ofrecido aquí puede servir para unir un argumento sólido, entonces el consentimiento no es en absoluto una manera importante de establecer la autoridad legitima política o jurídica. Esto pone fin al argumento basado en el consentimiento y demuestra que la autoridad de las Constituciones no puede derivar de la autoridad de sus creadores.

11 O que sólo tiene un papel secundario en el establecimiento de autoridades en tales áreas. 


\section{La mano muerta del pasado}

Nos enfocaremos al más conocido y poderoso argumento dirigido a separar la autoridad de las Constituciones de la de sus creadores. Nadie, sostiene el argumento, puede tener autoridad sobre las futuras generaciones. Por tanto, la autoridad de la Constitución no puede estar basada en la autoridad de sus creadores. Examinémoslo.

En primer lugar, dos cuestiones preliminares obvias: el argumento no es aplicable para las nuevas Constituciones. Pero las Constituciones están diseñadas para durar por un largo periodo de tiempo, y es justo concentrarse en las Constituciones más antiguas, como todas las Constituciones lo serán algún dia. Igualmente obvio, al menos prima facie, es que el argumento se aplica también a las leyes viejas. Pueden existir diferencias entre las Constituciones y las leyes ordinarias, que se originan en diferencias de su contenido. Pero dichas diferencias aún quedan por argumentarse. Ninguno de estos puntos afecta sustancialmente la fuerza del argumento.

La forma en que el argumento funciona es la siguiente: nosotros estamos buscando las condiciones bajo las cuales las Constituciones pueden ser justificadas y pueden gozar de autoridad (moral) legitima. Cualesquiera que sean, no puede ser el caso de que la autoridad de una Constitución antigua pueda derivar de la autoridad de sus autores. Dado que no existe una forma razonable de justificar la autoridad de cualquier institución que permita a ésta tener autoridad que se extienda hacia el futuro. ¿Qué tanto tiempo hacia el futuro puede extenderse la autoridad?, ¿el poder de la autoridad muere con ella? Si es así, ¿cuál es el tiempo de una autoridad institucional (es el periodo entre las elecciones, ya que el Congreso cambia cada dos o seis años, o es un cuerpo continuo que sólo morirá cuando exista un cambio fundamental en su Constitución)?, ¿ ¿ debemos pensar en el tiempo de vida de cada decreto individual dotado de autoridad, de cada 
estatuto o reglamento, o de cada disposición constitucional? Lo segundo parece ser el enfoque más acertado.

La autoridad de las instituciones para expedir decretos vinculantes se encuentra limitada en varios sentidos: algunas instituciones poseen autoridad para emitir reglamentos sobre la forma en que deben desarrollarse las actividades bancarias; otras pueden tener autoridad para ordenar el funcionamiento de las escuelas. Posiblemente, ninguna institución puede tener autoridad ilimitada en relación con todas las materias. De manera similar, la autoridad de cualquier institución se encuentra limitada por el rango de personas a quienes puede vincular. Algunas tienen autoridad sobre la gente en Kansas, otras sobre la gente en Francia, etcétera. Las consideraciones que limitan la autoridad de otros sobre nosotros, son más o menos del mismo orden de aquellas que establecen la inmoralidad de la esclavitud. Estas consideraciones establecen limites a la subyugación, a la subordinación de una persona a la voluntad de otra. Así como ellas lo hacen a través de la delimitación en cuanto a la materia y el rango de personas al cual tal poder se extiende, las mismas consideraciones limitan la validez temporal de sus directivas. Así como el rango de la materia y las personas variará en cada caso, de la misma manera la duración temporal de una directiva dotada de autoridad variará dependiendo de las circunstancias. Pero resulta razonable pensar que ninguna será válida cien años después de su aprobación. Esto es, si aún fuera válida en ese tiempo, lo anterior no será debido a la autoridad de su creador o autor original.

Resulta tedioso deletrear a detalle el argumento de esta conclusión. Pero sería de utilidad mencionar algunas orientaciones que ubican el tipo de consideraciones que están en juego. Éstas vienen en dos niveles: (a) los tipos de factores que determinan si las leyes son buenas o malas y (b) los factores que determinan la competencia de las autoridades políticas para lograr metas valiosas, los cuales, de este modo, establecen y limitan el alcance de sus poderes legíti- 
mos. Las consideraciones en ambos niveles deben ser combinadas para establecer los contornos de las autoridades politicas.

Explicaré el primer nivel mediante dos categorías (simplificadas en razón del propósito del presente análisis):

1) Algunas leyes, si son buen derecho, implementan ${ }^{12}$ directamente imperativos morales incondicionales. En este punto podría mencionarse la protección jurídica básica de la seguridad personal en el derecho penal y (en cierto grado) el derecho de daños en el ámbito civil. Algunos derechos civiles, como la libertad de religión o de pensamiento, son frecuentemente considerados como integrantes de esta categoría.

2) Muchas leyes, si son buen derecho, reflejan una distribución justa de oportunidades, recursos y servicios entre los miembros de la población, dadas las necesidades actuales, metas y aspiraciones, así como los recursos tecnológicos y económicos existentes y la organización social del momento. Las leyes cuyo valor es juzgado por este criterio deben estar sujetas a una revisión continua, debido a que los factores que las califican como satisfactorias se encuentran sujetos en cualquier momento a cambios frecuentes y significantes. Éstos incluyen el derecho social, las leyes urbanísticas, la legislación de protección al consumidor, los reglamentos de seguridad, las disposiciones sobre la salud, las leyes sobre educación, entre muchas otras.

Podría pensarse que las leyes pertenecientes a la primera categoria no requieren de ajustes frecuentes; han introducido en el derecho principios morales inmutables. Por tanto,

12 La claridad es importante aquí. Últimamente, todos los principios morales son o derivan de principios universales. Las leyes que pertenecen a esta categoría se encuentran justificadas por referencia directa a los principios de conducta universales, sin que medien argumentos complejos referentes a la forma en que se aplican a las condiciones sociales o económicas. 
podría argumentarse, la autoridad de los creadores de la ley para expedir este tipo de derecho trasciende en el tiempo. Pero tal argumento falla en ambos sentidos. Primero, mientras podría decirse que los preceptos morales que esas leyes imponen son inmutables, esto no significa que así lo sean las leyes que los protegen y ordenan. Tomemos un ejemplo simple: la injusticia moral cometida en la violación puede implicar la violación de un principio moral universal. Pero la regulación jurídica de la violación puede, correctamente, variar de lugar en lugar y de tiempo en tiempo. Para no ir más lejos, se aleja del principio universal la consideración de que la violación debe constituir un delito separado más que ser asimilada como una agresión seria. Generalmente no existe una razón convincente para que exista una relación "uno a uno" entre el tipo de injusticia moral y el tipo del delito. ¿En que casos y cuándo la motivación sexual debe determinar el tipo de ofensa?, ¿y en qué otros casos lo anterior debe importar sólo para la resolución?, ¿en qué casos y cuándo la penetración debe ser un parámetro para deslindar algunas ofensas sexuales de otras?, ¿en qué casos y cuándo debe importar la violencia? (la violencia no es un ingrediente necesario de la violación, de acuerdo a la mayoría de las jurisdicciones). Todas estas preguntas son sensibles a las condiciones sociales, a los entendidos sociales percibidos, a las consecuencias informales de las acusaciones penales, y a muchos otros factores que son tan variables como cualquiera. Por tanto, es poco sólido el primer paso en el argumento que sostiene a una autoridad duradera en el tiempo en relación con leyes que directamente implementan principios morales de conducta universales.

La segunda parte del argumento tampoco es más contundente. Para constatar esto, prescindiremos de la objeción que hice en el párrafo anterior. Asumamos que existe una categoría de leyes cuya validez es intemporal en la misma medida en que lo son los principios morales de los que derivan tales leyes. ¿Esto podría demostrar que tiempo después de su promulgación la autoridad de esas leyes se basa en la 
autoridad de sus creadores?, no. Este podría ser el caso si es que la autoridad de la ley tiene que derivar de la autoridad de sus creadores. Pero el hecho de que verdaderamente tengan, como suponemos, autoridad intemporal es contrario a tal postura. La autoridad intemporal de estas leyes depende de su contenido. Si su contenido es intemporalmente válido, lo es porque expresa principios morales universales. Estas leyes no son válidas intemporalmente porque fueron promulgadas por una institución social falible o aprobada por un referéndum. Para que la autoridad esté en condiciones de aprobar leyes válidas intemporales es necesario que cuente con un experto en moralidad, esto es, que tenga un conocimiento significantemente superior al que tiene la gente sujeta a las leyes de los principios morales abstractos. Mientras parece ser que contamos con expertos morales en algunos problemas especializados de moralidad aplicada (e.g., en relación al enredado tema del consentimiento a la experimentación médica), esto no es razón para pensar que cualquiera o cualquier institución puede ser experta en los principios abstractos de moralidad. Por tanto, la autoridad de las leyes que expresan tales principios no puede derivar de aquélla de sus creadores. Como indiqué en el primer paso del argumento, la autoridad de la ley deriva de aquélla de sus creadores en la medida en que las leyes determinan la forma temporal y la sensibilidad social con la que los principios morales se consagran en la ley. Pero ello no ayuda a demostrar que cualquiera puede tener autoridad para crear leyes que duren mucho tiempo. En general, es mucho más sencillo demostrar el caso de la autoridad limitada temporalmente en cuanto a las leyes del segundo tipo - aquéllas que de forma justa entre la gente destinan recursos, cargas y oportunidades-. Parece imposible formular estas leyes sin la necesidad de revisiones frecuentes. Dado que los creadores de la ley no pueden hacer buenas leyes que permanezcan así por un largo periodo, su autoridad no puede ser la razón de la autoridad de las leyes que anteriormente hicieron. 
Para apreciar este punto de forma más clara necesitamos pasar al segundo nivel de consideraciones, a los factores que determinan la competencia de las instituciones para funcionar bien y, por tanto, ser autoridades legítimas. Éstas han sido tratadas en los párrafos precedentes, pero ameritan estudiarse por separado, aunque brevemente.

En términos amplios, la autoridad política puede estar basada en uno o más de los siguientes tres tipos de consideraciones: experiencia, coordinación y valor simbólico. Las consideraciones de experiencia se encuentran por ejemplo en el caso del derecho de protección al consumidor, el derecho de seguridad en el trabajo y la mayoría de los reglamentos de seguridad. Estas consideraciones son también relevantes para muchas leyes que implementan directamente imperativos morales. La experiencia médica es relevante para la definición de la muerte, así como de la salud, enfermedad, herida, y conceptos similares. La experiencia y dominio psicológico es relevante para muchos aspectos del derecho de familia, etcétera. Pero suponer que la experiencia otorga a los creadores de la ley una autoridad intemporal, implica asumir que en el área relevante no se generará un avance del conocimiento ni un avance en su difusión. Y dichos avances niegan la experiencia y dominio de los anteriores creadores de la ley tanto frente a nuevos expertos (nuevos avances en conocimiento) o frente a la población en general (la difusión del conocimiento). Cualquiera los despojaria de autoridad legitima en tanto que la misma se basa en el elemento experiencia y dominio.

El derecho en su mayoría intenta lograr una coordinación social. El objetivo de lograr la coordinación predomina cuando el derecho busca asegurar condiciones sociales cuya realización depende de la conducta de un número de personas, por lo que cuando una parte considerable de ellos no se comporta en una forma propicia para el logro de las condiciones deseables, no existe razón, o por lo menos, no alguna que sea suficiente, para que tampoco otros se comporten de 
tal forma. ${ }^{13} \mathrm{El}$ derecho puede ayudar a asegurar la coordinación y para satisfacer estas funciones puede lograr una variedad de metas, incluso aquellas que pertenecen a la segunda categoria, mencionada líneas arriba. Puesto que las formas de coordinación deben de ser revisadas o ser reemplazadas por otras en circunstancias cambiantes, y puesto que existe un límite a la capacidad de cualquiera de estipular tales cambios con antelación, existe un limite, un limite temporal, a las leyes que tienen poder de hacer.

El tercer factor que puede dotar a las instituciones de autoridad es el valor simbólico de su posición como autoridad jurídica. En este punto tenemos que distinguir entre el valor de un cargo, del valor de tener a determinada persona o grupo de personas en tal cargo. Algunas personas obtienen posiciones elevadas de autoridad por haberse convertido en periodos de transición o de conflicto en símbolos de sus naciones. La posición de Vaclav Havel en los años inmediatamente posteriores a la democratización de Checoslovaquia (más tarde la República Checa) es un ejemplo de ello, y como éste existen muchos otros. Nuestro interés, de cualquier manera, se refiere al caso, menos común o menos fácil de documentar, en el que una institución ha adquirido valor simbólico. Podría decirse que la Corona posee tal posición en el Reino Unido. La Corona expresa y simboliza la unidad del país (el cual no es un Estado-nación). El significado simbólico de una institución es por si mismo una razón por la cual se reconoce que goza de prestigio moral legítimo. Mientras que el valor simbólico de otorgar un cargo a determinadas personas no afecta a la teoría de la autoridad, el hecho de que una institución tenga valor simbólico puede figurar en un argumento para sostener su autoridad legitima. Pero es poco probable que lo dote de una autoridad intemporal. Después de todo, existe una razón prima

13 Creo que esta noción de coordinación capta el significado natural del término utilizado en el discurso político. Lo he utilizado en este sentido al escribir sobre la justificación de la autoridad. Por consiguiente, éste varía del sentido artificial dado en la teoria de juegos. 
facie para no aceptar las leyes como válidas a menos que sean el tipo de ley que debemos tener. Que la institución que hace las leyes sea de valor no demuestra que las leyes que ha promulgado sean buenas. Incluso si el valor de la institución puede servir para un argumento que reconozca su autoridad, no es probable que éste pueda extenderse para otorgarle autoridad intemporal.

He presentado estas consideraciones conocidas debido a que son del tipo que tienden a establecer que ninguna institución humana tiene autoridad para hacer leyes que duren para siempre, o por un largo periodo de tiempo. Se deduce que incluso si las nuevas Constituciones pueden obtener su autoridad de la autoridad de sus creadores, las Constituciones antiguas, si es que son moralmente válidas, deben obtener su autoridad de otras fuentes. Mientras que con las leyes nuevas la autoridad de la ley deriva de la autoridad de sus creadores, la autoridad de leyes antiguas debe estar basada en otros elementos.

\section{PRINCIPIO Y PRÁCTICA EN LA JUSTIFICACIÓN}

\section{Dificultades referentes a hechos y normas}

Esta conclusión está sujeta a parecer paradójica en varios puntos. Ésta puede ser considerada como una que genera una paradoja de cambio: la Constitución que es válida hoy en los Estados Unidos es la que entró en vigor en 1789 y que ha sido reformada pocas veces desde entonces, de forma relevante entre 1865 y 1870 . Pero si mi conclusión es correcta, algunos podrian alegar, entonces algún tiempo después a su adopción, que la Constitución cayó en desuso y una nueva Constitución tomó su lugar. Pero éste es un simple malentendido. Mi argumento no sostiene que la Constitución cambió, sino que lo hicieran las razones para su validez. La misma ley puede ser válida por una variedad de razones, y éstas pueden cambiar sin que la misma ley cambie. 
Puede haber una preocupación más profunda en el trasfondo, la cual intento identificar. Una vertiente surge de la preocupación consistente en que mi argumento deja sin explicación el papel de los constituyentes originales y su importancia en la vida de algunos países. Un papel que no se agota simplemente en la vida temprana de una Constitución. Existen países, de acuerdo al argumento de la sección precedente, en los que el respeto a los autores de la Constitución es verdaderamente una fuerza política viva después de que la validez de la Constitución ha dejado de depender de su autoridad. Pero ello no requiere ser un obstáculo para aceptar el argumento. Los autores de una Constitución, especialmente los autores de la primera Constitución de un país, algunas veces se convierten en símbolos politicos, gente respetada que une al país y cuya sabiduría se convierte en la moneda corriente del argumento político. Tales hechos políticos - justificados o no- no necesitan tener relación con la más limitada cuestión sobre la legítima autoridad de las Constituciones, aquellos casos en que tienen tal autoridad. Tampoco es una objeción al argumento el que la sabiduria de los constituyentes sea utilizada para interpretar una Constitución, pues como se verá más adelante, las prácticas interpretativas locales hasta cierto punto se autolegitiman.

Pero éstas no son las únicas preocupaciones que provoca el argumento adelantando en la sección precedente. Éste también da origen a nuevas preguntas sobre las relaciones entre el derecho y la moralidad. Nosotros reconocemos el carácter dual del derecho. Por un lado, es un hecho social más que moral que el derecho de un país o de otro es de una manera y no de otra. Este aspecto del derecho deriva de diversas características fundamentales para nuestro entendimiento de su naturaleza: primero, explica cómo pueden haber no sólo buenos derechos, también derechos malos, y asimismo derechos y gobiernos que carecen de toda legitimidad (moral), así como aquéllos que son (moralmente) 
legítimos. ${ }^{14}$ Segundo, explica por qué no podemos saber qué es el derecho en un determinado país, o sobre una determinada materia, simplemente indagando sobre lo que debe ser. Tercero, explica cómo dos personas, una que cree que el derecho es legítimo y otra que niega su legitimidad, pueden llegar a un acuerdo sobre lo que es el derecho. Lo que explican éstas y otras características simples pero profundas del derecho es que éste es un hecho social, lo que significa que su existencia y contenido pueden establecerse como hechos sociales, sin recurrir a argumentos morales. ${ }^{15}$ Por otro lado, el derecho presenta un aspecto diferente, normativo. El derecho busca guiar la conducta de la gente y lo pretende con una autoridad moral. Y no obstante que puede no gozar de tal autoridad, debe ser capaz, en principio, de hacer válido su reclamo. Esto es, el derecho es una institución social que pretende gozar de autoridad moral sobre sus súbditos y es en principio, y por su propia naturaleza, capaz de gozar de tal autoridad.

Una teoría jurídica debe explicar esta naturaleza dual del derecho, como hecho ${ }^{16}$ y como norma. La doctrina de que la autoridad (moral) de todo el derecho deriva de la autoridad (moral) de sus autores proporciona una forma fácil de lograrla. Existen, de acuerdo con la versión simple de esta explicación, dos pasos en el establecimiento de la validez moral del derecho. Primero, se tiene que establecer la autoridad moral de los creadores de la norma para crear derecho y posteriormente se tiene que establecer como cuestión de hecho social que tales creadores de la norma hicieron

14 Las leyes malas, es decir, leyes que deben ser abrogadas o reformadas pueden tener legitimidad moral; esto es, uno puede tener la obligación moral de aplicarlas o de obedecerlas.

14 Como es bien sabido, esta tesis requiere de una redacción cuidadosa que puede incorporar aclaraciones a las que no tenemos que adentrarnos. Puede, por ejemplo, ser el caso de que sólo las criaturas que tengan capacidad de conocimiento moral y vida moral pueden tener la habilidad de identificar y entender hechos sociales.

16 Por razones de conveniencia sigo la convención de contrastar el hecho con la norma, o con moralidad o valor. Mi intención no consiste en decir que no existen hechos morales. 
esta ley en particular - esto es, una ley con este contenido en concreto-. Los dos aspectos del derecho son, de esta manera, separados en estas dos etapas donde se establece la autoridad legítima del derecho. De acuerdo con esta explicación, la autoridad moral del derecho, si la tiene, deriva en parte de su facticidad. El hecho de que contenga tales o cuales hechos llega a ser el núcleo del argumento moral para su autoridad: cuando estos hechos presentan tal o cual naturaleza, los argumentos morales dotan al derecho con legitimidad moral, pero cuando presentan esta o aquella naturaleza, no existe argumento moral que pueda legitimar el derecho. Esto explica porqué el contenido del derecho puede ser establecido independientemente de cualquier cuestión referente a su legitimidad moral. Aquí, la moralidad sigue a los hechos: se aplica a hechos establecidos independientemente.

Pero todo esto presupone que los legisladores, como instituciones sociales, median entre el derecho y la moralidad. Ellos proporcionan el ancla fáctica del derecho; son parte de este aspecto fáctico, el cual posteriormente es sometido al escrutinio moral. Esta idea, simple en gran parte, es correcta, pero innecesariamente se enfoca en la legislación como la única característica que permite una explicación que combina estos dos aspectos del derecho. Una explicación adecuada sobre la naturaleza dual del derecho tal y como la he sugerido $^{17}$ requiere a) que el contenido y existencia del derecho sean determinados por fuentes sociales y b) que el argumento moral para la autoridad del derecho dependa de la naturaleza vigente de las fuentes sociales. No es necesario que las fuentes sociales tomen la forma de legislación. Ellas pueden ser producto de la costumbre, el common law, opiniones juridicas, entre muchas otras. ${ }^{18}$

17 Y existen posibles alternativas que se desvian de la forma en que los hechos y las normas se encuentran separados en dos etapas distintas, y que permiten relacionarse en determinadas circunstancias.

18 No todo hecho social puede ser una fuente del derecho. Debe satisfacer otras condiciones que no hay necesidad de abordar aquí. 
Puede ser de ayuda reflexionar sobre las implicaciones, que para las relaciones entre el derecho y la moralidad, que tiene este aspecto dual del derecho. Los dos aspectos del derecho están reconciliados por el hecho de que la aplicación de la moralidad desempeña una mediación producto de la aplicación a hechos sociales generadores de normas. Este es un tipo especial de mediación. No es de sorprenderse que nuestros derechos y obligaciones morales dependen de cómo las cosas son entre nosotros y del mundo en el cual vivimos: "No debo hacer esta o tal acción, porque existe gente a mi alrededor que pudiera resultar lastimada", "Debo ofrecer asistencia a esta persona, ya que se ha caido y necesita ayuda", "Debo prestarle el coche al vecino la siguiente semana, pues se lo prometi”. Estos son ejemplos comunes de la manera en que las implicaciones de la moralidad dependen de hechos. Pero ninguno de ellos constituye hechos generadores de normas.

No así en sus relaciones con el derecho. Aquí la moralidad se aplica sancionando - o condenando- normas generadas por hechos sociales de la legislación, costumbre, etcétera. ¿Por qué debe darse esta mediación especial cuando se trata del derecho?, no es porque todas las consideraciones morales tienen que tener una mediación producto de normas socialmente generadas. Las razones de esto son, por lo menos en parte, bien sabidas. El derecho puede ayudar a asegurar la coordinación social y a proporcionar a la gente los beneficios de la información que no se encuentra generalmente disponible. La habilidad de beneficiarse de tal información y de asegurar la coordinación social es a menudo ventajosa o incluso, necesaria para alcanzar metas valiosas e incluso, para cumplir con requerimientos morales. Pero ¿por qué la gente no puede coordinar sus acciones o compartir información sin la mediación de las normas jurídicas? Si las normas morales son suficientes para justificar la coordinación y compartir información, ¿por qué la gente no actúa y logra estas metas simplemente por estar conscientes de las razones morales para hacerlo?, algunas veces lo 
hacen y cuando es así la mediación jurídica no es necesaria; pero otras no lo hacen por razones que todos conocemos. Dentro de las razones que han atraído mucha atención en estudios recientes están $a$ ) el desacuerdo sobre qué metas uno tiene buenas razones (morales) que perseguir, b) problemas colectivos de acción y c) la indeterminación de las razones morales. Estos factores dificultan algunas veces garantizar la coordinación y compartir la información, excepto a través de la intervención de autoridades sociales o jurídicas cuya legitimidad es reconocida y quienes poseen poder suficiente para imponer un grado razonable de cumplimiento a aquellos que dudan de su legitimidad o que, de otra manera, pueden estar tentados en ignorar o actuar de forma indebida, etcétera.

Tal vez, el último factor mencionado es el menos común. ${ }^{19} \mathrm{El}$ pensamiento subyacente es simple: si elimináramos la ignorancia, el desacuerdo sobre las metas morales o las mejores formas de implementarlas, los malos hábitos, a los gorrones u otras situaciones similares, y si las consideraciones morales mencionaran de manera univoca la forma en que se deben organizar las cosas en la sociedad, entonces la gente seguiría tales consideraciones. Pero cuando las consideraciones morales subdeterminan las metas a seguir o los medios para buscarlas pueden encontrarse dificultades adicionales en el aseguramiento de la coordinación y para superarlas la mediación del derecho es de ayuda, y en algunos casos, necesaria. Piénsese en un ejemplo hipotético: asúmase que la teoría de la democracia se basa sólo en un principio general (por ejemplo, que un gobierno democrático es aquél donde existen mecanismos jurídicos formales, sensibles a los deseos de los gobernados para determinar el contenido de las politicas y la identidad de aquellos a cargo de implementarlas, y que en la medida de lo posible no se otorgue un poder político mayor del que goza cualquier otro). De esto se deduce que puede haber en principio

19 En tiempos recientes su importancia ha sido enfatizada por Finnis, J., Natural Law and Natural Rights, Oxford, Oxford University Press, 1996. 
muchas formas moralmente legítimas de gobiernos organizados democráticamente: repúblicas federales y monarquías constitucionales, circunscripciones electorales de un solo miembro y sistemas de representación proporcional, gobiernos parlamentarios y sistemas de elección presidencial, etcétera. Todos estos sistemas radicalmente distintos serian sistemas de gobierno democráticamente adecuados; posiblemente las circunstancias de un país u otro harán alguno o varios de ellos inadecuados para tal país. Pero - este es el supuesto subyacente en el ejemplo- tales consideraciones no reducirán el número de sistemas aceptables en uno solo.

En tales circunstancias, la mediación a través del derecho juega el papel de concretizar principios morales - esto es, darles el contenido concreto que deben tener a fin de que la gente sea capaz de seguirlos-. En nuestro ejemplo un país debe tener uno $u$ otro sistema de gobierno democrático. Así, es el derecho quien determina cuál de ellos tiene. Por supuesto, para hacer eso el derecho debe ser materia de hechos sociales, no moral. Su objetivo y propósito, tal y como lo explica el ejemplo, consistente en complementar a la moralidad. Para hacer eso, su contenido no puede estar determinado por consideraciones morales. Debe reflejar prácticas sociales o tradiciones o algún otro hecho social.

Estas consideraciones demuestran cómo el contenido del derecho se encuentra determinado por hechos y no por normas, lo cual no sólo explica las cuestiones obvias que en relación al derecho mencioné anteriormente, sino que también contribuye a una explicación del derecho de cómo éste es capaz de llevar a cabo algunas de sus funciones básicas (tales como afrontar desacuerdos sobre moralidad y concretizar principios morales). Las mismas consideraciones explican cómo algunas veces resulta ventajoso, desde el punto de vista moral, que la mediación se realice a través de la legislación, mientras que en otras circunstancias es mejor que sea a través de otros medios. La legislación sería el método preferido de mediación cuando los cambios en la ley 
lleguen a ser necesarios de manera frecuente o repentina y cuando las reformas a la ley que lleguen a ser deseables, puedan elaborarse a través de la deliberación o negociación. Pero otras formas de mediación son preferibles cuando los ajustes a los cambios puedan ser lentos y graduales, en los que ni la deliberación ni la negociación pueden ser útiles y especialmente cuando es importante asegurar la continuidad, o bien desanimar un cambio prematuro o precipitado, o incluso para negar a los grupos de interés la posibilidad de chantajear o lograr que el resto de la comunidad (dé su brazo a torcer) en cuanto a la aceptación del cambio, etcétera. En conclusión, la mediación no debe llevarse a cabo sólo a través de la legislación, sobre todo cuando la materia es de importancia constitucional, esto es, cuando debe formar parte de una Constitución consolidada.

\section{Legitimidad a través de la práctica}

La discusión de las relaciones entre norma y hecho es aleccionadora. Pero la conclusión parece indicar que es problemática. Permítanme exponerlo en la forma más paradójica: las Constituciones, al menos las más antiguas, no obtienen su autoridad de la autoridad de sus autores, pero no hay necesidad de preocuparse sobre la fuente de su autoridad, se auto-validan por sí mismas. Son válidas sólo porque están allí, consagradas en las prácticas de sus países.

Obviamente decirlo así distorsiona las conclusiones a las que hemos llegado en la discusión anterior. Una condición aún más importante debe ser añadida: en la medida en que permanezcan dentro de los limites establecidos por los principios morales, las Constituciones se auto-validan ya que su validez deriva del hecho de que ellas existen. Debe ser añadido que esta conclusión procede si la moralidad subdetermi- 
$n a^{*}$ los principios referentes a la forma de gobierno y al contenido de los derechos individuales consagrados en la Constitución. No he dicho nada para apoyar la tesis de la subdeterminación, ni lo haré en este ensayo. Sin embargo, puesto que creo que la tesis de la subdeterminación es viable, ${ }^{20}$ sólo expondré algunas implicaciones de esta posición.

La principal implicación es que dentro de los amplios límites fijados por los principios morales, el derecho basado en la práctica se auto-justifica. La Constitución de un país es una Constitución legítima porque es la Constitución que éste tiene. Esta conclusión debe ser explicada y revisada antes de que la podamos aceptar.

En primer término, el hecho de que los principios morales subdeterminen el contenido de las Constituciones, no significa que la gente o las instituciones que adopten estas Constituciones o las reformen no lo hagan por alguna razón, o que ellos no puedan tener razones adecuadas para sus decisiones. Lo único que se sigue es que sus razones no son de principios morales (i.e., no son los principios morales que determinan qué Constitución es legítima y cuál no). Por ejemplo, un gobierno puede apoyar un cambio en la Constitución, que no es requerido con base en principios morales, sólo debido a que tal cambio es popular con respecto al electorado o por la razón de que tal cambio ofrecerá alguna ventaja al grupo que está comúnmente alejado o resentido y por tanto, podrá ayudar a reconciliarlo con el Estado o con la mayor parte de la sociedad. Alternativamente, dicho cambio puede ser viable sólo por que es un cambio en sí mismo, y un cambio infundirá un nuevo espí-

\footnotetext{
* N. de T. La tesis que se avanza en este punto es la "underdetermination thesis" y hemos optado por traducir "underdetermination" como subdeterminación, en el entendido de que subdeterminación o "underdetermination" tienen como objetivo dar la idea de una determinación parcial no total de algo, una determinación de algunos aspectos no de todo.

$20 \mathrm{El}$ hecho de que la moralidad subdetermine el contenido de la Constitución parece seguirse de la tesis de que los valores morales son extensiva y significativamente inconmensurables. He analizado este asunto en diversas publicaciones, especialmente en The Morality of Freedom, capitulo13 y en "Incommensurability and Agency", en Chang, R. (ed.), Incommensurability, Incomparability and Value, Cambridge, Mass., Harvard University Press, 1998.
} 
ritu en la sociedad que ha quedado moribunda y estancada, o asimismo, porque el cambio lleva a algunas personas a perder poder y a otras a ganarlo, y resulta adecuado para reducir el poder de la gente o de los grupos que actualmente lo ostentan en un país determinado.

Estas razones y muchas otras son en un sentido morales y pueden ser perfectamente viables para adoptar cambios en una Constitución. El punto es que ninguna de ellas es lo que llamo una "razón de mérito", ninguna procede de la conveniencia moral de cualquier postulado constitucional. Denominaré a las razones que tienen que ver con el mérito de estar sujeto a un determinado postulado constitucional "razones de mérito", para distinguirlas de las razones que se tienen para adoptar, o reformar un postulado constitucional y que no derivan del beneficio de estar sujetos a él. Por el contrario, todos ellos son ejemplos de cómo una reforma constitucional puede estar justificada por razones que no tienen relación con el mérito del cambio constitucional que justifican. Éstos también son ejemplos de cómo los asuntos politicos ordinarios, incluso aquellos asuntos políticos de alcance relativamente corto, pueden tener un papel legítimo en las políticas de una Constitución.

El aspecto auto-legitimador de la práctica no se descarta por el hecho de que los actos para y en contra de una reforma constitucional puedan ser llevados a cabo por buenas razones. Debido a que el tipo de razones ejemplificadas no son razones de mérito y tienen efectos sobre el mérito del contenido de la Constitución, éstas no tienen que ver con su legitimidad. Lo anterior, se encuentra determinado fundamentalmente por las razones de mérito que muestran que el contenido de la Constitución es moralmente aceptable, y nada en estos ejemplos niega la tesis de que las razones de mérito generalmente subdeterminan el contenido de la Constitución, lo cual nos lleva a la conclusión de que 
dentro de los límites que establecen, las Constituciones por su propia existencia se legitiman. ${ }^{21}$

\section{Estabilidad y continuidad}

Introduje la idea de auto-legitimación, del efecto legitimador de la práctica a través de la reflexión en el hecho de que los principios morales subdeterminan el contenido de las Constituciones, y que la práctica "se ocupa de esta labor". Pero como es bien sabido, el poder auto-legitimador de la práctica no se reduce a esto. Las convenciones son, quizás, el ejemplo más familiar. Las convenciones ejemplifican una categoría mayor en la que el comportamiento es justificado si, y normalmente sólo si, una práctica general existe: uno no debe pisar el césped si existe una práctica general de no hacerlo. Que esas cosas pasen de determinada manera hacen que sea correcto o bueno el que sigan haciéndose de esa manera.

Una preocupación de naturaleza similar es la de la estabilidad. La necesidad de asegurar la estabilidad es, en sí misma, indiferente al contenido de las prácticas constitucionales prevalecientes en cualquier tiempo o lugar. Cualesquiera que sean, la preocupación por la estabilidad indica que deben perpetuarse. La estabilidad no es siempre una ventaja. En el apartado anterior, hice notar que reorganizar las cosas puede ser conveniente cuando esto puede cambiar una poderosa estructura corrupta o moribunda e infundir en un país un sentido de energía y esperanza, etcétera. Sin embargo, la estabilidad es con frecuencia conveniente por muchas razones. Recuérdese que aquí la referencia hacia la naturaleza auto-legitimadora de la Constitución no es sólo a la existencia jurídico-formal de la Consti-

21 Esta conclusión puede ser reforzada. Incluso cuando una Constitución alternativa es de alguna manera mejor que la que tenemos, el hecho de que es la que tenemos la hace legítima. Las consideraciones que apoyan esta conclusión y que le dan mayor sentido nacen del costo que implica el cambio, y de la presunción de lo conservador. Dichos temas son discutidos más adelante. 
tución, sino a la Constitución tal y como existe en las prácticas y tradiciones del país respectivo. Las Constituciones están pensadas para proveer un contexto para la vida pública de un país, dándole dirección y forma. Para lograrlo, los conocimientos de la Constitución deben estar asegurados. Esto requiere un conocimiento no sólo del texto, sino también de su significado, es decir, conocimiento de las prácticas constitucionales del país. Hasta que la gente lo asimile y se ajuste a ella, un cambio radical en la Constitución desbarata esas prácticas. Lo anterior genera consecuencias en los diferentes aspectos de la vida pública y lo que suele ocurrir es una incertidumbre momentánea en relación a la manera en la que la reforma o el cambio afectarán los diversos aspectos de la práctica constitucional. Dicha incertidumbre afecta la habilidad de la gente para funcionar. Esto es peor si se genera un temor hacia los cam- bios continuos, llevando a un sentido de dislocación y falta de dirección.

Estos son algunos de los elementos comunes para preferir la estabilidad a la inestabilidad. Lo cual no significa un rechazo al cambio, pero genera razones para preferir la continuidad, a menos que existan razones realmente buenas para emprender modificaciones. También se suelen agregar al poderoso argumento conservador: mientras que es posible predecir las consecuencias directas de los cambios pequeños en las prácticas sociales y jurídicas, los cambios que toman lugar dentro del marco existente y no las desbaratan, es imposible predecir el efecto de los cambios radicales y a gran escala. Lo que sí sucede es que son susceptibles de afectar el marco jurídico y social, el cual constituye las condiciones de trasfondo que hacen posibles las predicciones de los acontecimientos sociales. Por tanto, mientras que una reforma radical pueda estar inspirada en razones convincentes para generar condiciones sociales distintas, no existe una razón adecuada para creer que esto traerá consigo dichas consecuencias deseadas. Esto no intenta ser un argumento en contra del cambio y las reformas radicales. No in- 
tenta demostrar que el cambio radical sea posiblemente lo peor. Pero sí elimina muchas de las razones que la gente suele emplear para defender un cambio radical. Tomado junto con las ventajas de la estabilidad, esto se viene a sumar a determinadas actitudes conservadoras que en ocasiones se expresan mediante la alusión a que en las sociedades relativamente estables y decentes, existe una presunción a favor de la continuidad en relación a la cual todas las propuestas de cambio deben ser juzgadas.

En general, el argumento de estabilidad y la subdeterminación de los principios constitucionales por la moralidad se combinan para establecer el aspecto auto-legitimador de las prácticas y las tradiciones constitucionales. ${ }^{22}$ Sin embargo, mezclarlos a los dos es correr el riesgo de oscurecer las dos diferencias fundamentales entre ellos.

Primero, el argumento de la subdeterminación significa que dentro de los amplios limites impuestos por principios morales, la mera existencia de una Constitución establece que es una buena Constitución para el país respectivo. Otros principios se pudieron haber contemplado, pero dado que no fueron adoptados, no son ellos sino los reflejados en las prácticas de dicho país los que constituyen su Constitución legítima. La conveniencia de estabilidad no establece que la Constitución sea legitima. Esto se aplica aun a las Constituciones ilegitimas. Incluso las desventajas de estabilidad también tienen una relevancia, aunque son superadas por otras consideraciones.

Segundo, mientras que el argumento de subdeterminación permite que las Constituciones se encuentren auto-legitimadas, lo anterior no constituye una razón para no enmendar la Constitución. La Constitución es legítima, pero también lo serian las muchas alternativas que pudiéramos tener. Los argumentos para la estabilidad, por otro lado, mientras que no demuestran la legitimidad de la Constitu-

22 Siempre se debe recordar, y no repetiré el punto de nuevo, que el aspecto auto-legitimador de las prácticas constitucionales se encuentra sujeto a su adecuación a lo que es moralmente aceptable. 
ción existente, sí demuestran la existencia de razones para no cambiarla.

Las cosas son diferentes si la Constitución es moralmente legitima, es decir, si adopta una de las formas de gobierno permitidas, esto es, si se encuentra dentro de lo permitido por las consideraciones morales. Cuando es así, los argumentos de subdeterminación y de estabilidad se combinan para legitimar la Constitución y proporcionar una razón para mantener la tradición constitucional tal y como es.

¿Que papel tienen los autores de la Constitución, si lo tienen, en cuanto a proveerla de legitimidad?, su papel puede ser de una enorme importancia práctica, aunque se trata de un papel secundario desde el punto de vista teórico. Básicamente ellos contribuyen a iniciar la tradición constitucional, y a veces su reputación ayuda a mantenerla así. Ellos pueden dotarla de autoridad en sus primeros años y el respeto en que se tienen dichos autores puede ser de gran importancia para determinar la voluntad de la población y de sus grupos políticamente activos para que se sometan a ella. Dicha voluntad es crucial, tanto para la supervivencia como para la legitimidad de la Constitución. Pero sólo en la medida en que contribuya a ubicar a la Constitución dentro de los límites moralmente permitidos.

\section{PARTE SEgunda. InTERPRETAR CONSTITUCIONES}

\section{INTERPRETAR LA CONSTITUCIÓN: SOBRE LA NATURALEZA DE LAS DOCTRINAS INTERPRETATIVAS}

Podemos tomar la interpretación constitucional como una práctica establecida y limitarnos a estudiar cómo se lleva a cabo en diferentes países. Tal estudio no carecería de interés; sin embargo, desde un punto de vista teórico sus beneficios serian limitados. Un estudio basado en este tipo de explicación y clasificación de las técnicas interpretativas daría como resultado una abundancia en estilos y téc- 
nicas interpretativas que varian en los países y cambian con el paso del tiempo; lo cual también revelaría los desacuerdos entre los jueces acerca de los métodos y técnicas de interpretación constitucional apropiados. Finalmente, demostraria que frecuentemente lo que los jueces dicen que hacen y lo que hacen es distinto. La práctica de algunos jueces no concuerda con sus afirmaciones generales sobre la naturaleza de la interpretación constitucional.

Quizás, en parte por estas razones, muchos filósofos del derecho se han abstenido de escribir acerca de la interpretación o han ofrecido explicaciones normativas de la interpretación en general y de la interpretación constitucional en particular. ¿Esto traiciona la labor de explicar el derecho como es en lugar de cómo debe ser?, no necesariamente. Primero, la interpretación jurídica es mucho más que un método para establecer lo que es el derecho. Cuando es usada por los tribunales y por los abogados, por comentaristas y académicos, quienes se enfocan a las interpretaciones que los tribunales debieran adoptar, la interpretación jurídica también es una herramienta para desarrollar, cambiar y modificar el derecho. Segundo, mientras es generalmente aceptado (por razones que emergerán a continuación) que tiene sentido el seguir los métodos interpretativos establecidos, en la medida en que existen, también es generalmente aceptado que las interpretaciones están sujetas a una evaluación objetiva, es decir, que algunas son defendibles y otras no lo son. ${ }^{23}$ Además, es parte de la práctica de la interpretación jurídica, como lo es en muchos países, que los tribunales no están obligados a seguir técnicas interpretativas arraigadas si puede probarse que son erróneas o menos deseables que otras alternativas. Ellos pueden modificarlas o cambiarlas por algunas mejores. Esto es el caso, por ejemplo, en las jurisdicciones del common law. En tales países el estudio de las interpretaciones viables es también parte del estudio del derecho como es. Pero se tra-

23 Como resulta evidente, esto no implica aceptar que para cada pregunta sobre la interpretación del derecho existe sólo una respuesta aceptable. 
ta de un estudio de un aspecto muy especial del derecho, uno que delimita algunas de las facultades creadoras de los tribunales y de las circunstancias para su uso legítimo.

Por tanto, cuando reflexionemos sobre la interpretación constitucional, debemos empezar, no del hecho de que ciertos métodos de interpretación son usados, y otros no, sino por la pregunta: ¿por qué es la interpretación tan importante para la adjudicación constitucional? La respuesta, como siempre sucede cuando existe una razón para recurrir a la interpretación, se basa en una combinación de razones para respetar la Constitución como existe y razones para dejar abierta la posibilidad de que necesite ser reformada, modificada o desarrollada con la finalidad de remover los defectos que tiene o que emergen en la medida en que el gobierno o la sociedad que gobierna cambie a través del tiempo.

Debe ser enfatizado que este aspecto dual de la interpretación (que busca tanto dilucidar el derecho como es, así como desarrollarlo y mejorarlo) no es exclusivo de la interpretación jurídica. Dicho aspecto dual es una característica de la interpretación en general, en tanto que ésta busca ser verdadera a algo original que se está interpretando y a la vez está abierta para su innovación. En las artes escénicas como en el teatro, por ejemplo, los buenos guiones interpretan el texto y frecuentemente expresan el punto de vista de los actores al mismo tiempo. Esto no significa que todas las buenas interpretaciones son innovadoras, simplemente que las interpretaciones pueden ser innovadoras y por tanto, están siempre abiertas a esta posibilidad. Este no es lugar para considerar la naturaleza de la interpretación en general. ${ }^{24}$ Pero podríamos reflexionar sobre las razones por las que la interpretación constitucional debe presentar este aspecto dual.

La razón de esta perspectiva hacia atrás de la interpretación constitucional, nos lleva al principio con el que comen-

24 Para ver las razones que niegan que cada vez que entendemos algo lo interpretamos, véase la que dice Marmor sobre la postura de Wittgenstein, esto en Interpretation and Legal Theory, Oxford, Oxford Universtiy Press, 1996, pp. 155-176. 
zamos. Las doctrinas de la interpretación constitucional, tal y como fue el supuesto desde el principio de este estudio, están, por lo menos en parte, basadas en la doctrina de las fuentes de la autoridad de las Constituciones. Dado que la autoridad de una Constitución, consagrada por un largo tiempo, se basa principalmente en la conveniencia de asegurar su continuidad, la misma continuidad debería informar también de los criterios de interpretación constitucional. Para asegurar la continuidad, la interpretación debe mirar hacia atrás, de esta manera sería fiel a la Constitución tal como existe en ese momento. Si así fuera, ¿esta consideración no debería dominar la interpretación constitucional con exclusión de cualquier otra?, la importancia moral de los asuntos decididos sobre casos constitucionales no permitiria que esto pasara. Los tribunales cuyas decisiones determinan la suerte de mucha gente deben basarse en consideraciones viables desde el punto de vista moral. Nada más podria justificar sus decisiones. Si admitimos esto, ¿no se deduce del anterior argumento el que la decisión moralmente correcta es aquella que está basada en "mirar hacia atrás" —esto es, aquella que no hace más que determinar el contenido (o los puntos importantes) de la Constitución como se encuentra en el momento-? Este puede ser el curso correcto que deben tomar, pero sólo cuando esto sea moralmente requerido, o al menos, sea moralmente razonable el que la decisión se base en consideraciones de continuidad sobre cualesquiera otras.

En otras palabras, dado el impacto que tienen las decisiones constitucionales, como muchas otras decisiones juridicas, en la vida de las personas, su justificación se encuentra sólo si son moralmente correctas. Como vimos, las consideraciones de continuidad presentan gran importancia moral, y son las consideraciones primarias en la determinación de la legitimidad continua de las Constituciones. Pero raramente éstas son las únicas consideraciones morales que afectan un asunto. Cuando no lo son, los tribunales deben tratar de llegar a resoluciones que satisfagan, tanto 
como sea posible, todas las consideraciones relevantes, y cuando no sea posible satisfacer completamente todas, deben esforzarse por satisfacerlas tanto como sea posible, dada su importancia respectiva. Por tanto, aunque la conveniencia de continuidad que interesa en el asunto prevalecerá sobre cualquier otra, a menudo éste no será el caso, e incluso cuando la continuidad no anule todas ellas, debe ser tomada en cuenta en la mayor medida posible. Entonces, en tales casos, los tribunales deben interpretar la Constitución impulsados por las consideraciones de continuidad, pero también deben dar peso a otras consideraciones morales. Esto es, sus interpretaciones también deben mirar hacia adelante. Nada de esto implica que todos los defectos de una Constitución se deban corregir a través de interpretaciones ingeniosas, lo que estoy diciendo es que algunas veces esto es posible.

Pero aún así, puede presentarse la objeción de que mi tesis pasa por alto el hecho de que la doctrina de la interpretación constitucional es una doctrina juridica, no moral. Cualquiera que sea el mérito de mis afirmaciones, según dice la objeción, son irrelevantes para un entendimiento de la interpretación constitucional. Esa doctrina es una doctrina jurídica y no hay nada que los jueces puedan hacer más allá que seguir las doctrinas de interpretación que son obligatorias para ellos de acuerdo con el derecho de su país. Permítaseme reconocer que hay algo en la objeción. Los jueces que siguen mis afirmaciones aquí desarrolladas sobre la interpretación pueden encontrarse obligados a desobedecer la ley de su país. Esto es el resultado de un enfoque hacia la interpretación constitucional que estoy desarrollando y que, a falta de un mejor término, podemos llamar un enfoque moral. El derecho de cualquier país puede ser de diversas maneras contrario a la moral. Una de estas maneras es la existencia de reglamentos locales vinculantes que prohíben a los tribunales seguir cualquier interpretación moralmente aceptable. 
No estoy proponiendo que las observaciones en este ensayo sean como un sustituto del análisis de las reglas y doctrinas de interpretación prevalecientes en este país o en otro. Esta es desde luego una tarea importante para los interesados en el derecho de los países en cuestión. Sin embargo, sería falsa modestia decir sólo que el tema de mi discusión es distinto; también pretendo que tenga importancia. Permítanme recapitular: primero, aunque existan razones para que las personas estén interesadas en este o en otro sistema jurídico y en sus reglas de interpretación, no existe una teoría universal de interpretación que sea aplicable para todos, excepto como una teoría normativa - esto es, que sostenga cómo debe ser la interpretación-. Segundo, les parezca o no, los tribunales se enfrentan a problemas morales y deben desarrollarse de una forma sancionada por la moralidad. Esto puede llevarlos a estar en conflicto con lo dispuesto por el derecho. Tercero, usualmente los propios medios de interpretación de las Constituciones son controvertidos. Cuarto, generalmente los tribunales tienen poder para adoptar nuevas formas de interpretación del derecho y de revisar, cuando tienen buenas razones para hacerlo, las ya establecidas.

Los últimos dos puntos se encuentran interconectados, y ambos son el resultado de un hecho que aún no ha sido mencionado: en el nivel más básico no existen, y no pueden existir, formas específicas de interpretación jurídica. Por supuesto, la mayoría de los sistemas jurídicos tienen reglas de interpretación que se encuentran en la legislación o en precedentes y que son especiales para ellos. Pero la mayoría de la interpretación no depende y no puede depender de las mismas. Esto no sólo se debe a que las reglas de interpretación por sí mismas a menudo requieren ser interpretadas. Se debe fundamentalmente a que los problemas de interpretación raramente son problemas del significado de un término o de una frase. A menudo se trata de preguntas sobre la interpretación de oraciones, o de artículos en códigos o en Constituciones o de doctrinas politicas y morales, y es- 
tas preguntas pueden surgir en lugares inesperados. Ningún conjunto de reglas de interpretación puede lidiar con todas ellas. Lo mismo es válido para las reglas de interpretación implícitas en una cultura jurídica en lugar de lo que se encuentra explicitamente articulado en sus leyes. Tales reglas no pueden resolver todos los problemas posibles de interpretación. Frecuentemente la interpretación es sólo una cuestión de razonar en torno a un punto de vista razonable en el contexto de varias consideraciones, algunas de las cuales se agrupan y otras colisionan. No existe manera de reducir tal razonamiento a la aplicación de las reglas, o de otras normas, ni tampoco existe otro modo de eliminar la necesidad y la conveniencia de la interpretación que consiste en y se origina de tal razonamiento.

Esto explica por qué el derecho de interpretación, es decir, las reglas y doctrinas de interpretación vigentes en un país determinado, aunque útiles, no pueden contener todo lo que se puede y se necesita saber sobre la interpretación legal o constitucional. En última instancia, una explicación de la interpretación constitucional tiene más que ver con entender el razonamiento jurídico o el razonamiento constitucional que con la comprensión de cualquier doctrina específica de este o de aquel país. El razonamiento que busca establecer el significado de una ley, un trabajo de arte, literatura, religión, o cualquier otro y que combina el respeto de su expresión original o de su significado tradicional o actual con su disposición a la innovación, es interpretativo. Por las razones expuestas, el razonamiento constitucional es en gran medida un razonamiento interpretativo. Pero las explicaciones sobre el razonamiento son explicaciones sobre las creencias y son explicaciones normativas universales, específicas para una localidad o materia sólo en los detalles de su aplicación.

Todo esto fue dicho para desarrollar la importancia de una explicación normativa de la interpretación constitucional, una explicación que va más allá del estudio de las reglas y doctrinas de interpretación establecidas en un país o 
en otro. Pero el camino que han tomado estos comentarios sugiere otra objeción en relación a la idea de que puede existir un estudio general de la interpretación constitucional. Si el estudio de la interpretación es únicamente el estudio sobre el razonamiento limitado por las condiciones mencionadas anteriormente y si el estudio de interpretación constitucional es sólo el estudio de tal razonamiento cuando es aplicado a las Constituciones, ¿hay algo más que pueda ser dicho, aunado a la poco útil recomendación de que al interpretar Constituciones uno debe razonar bien?, tal vez exista un criterio general de razonamiento y tal vez, incluso, un criterio general de razonamiento interpretativo. Pero una vez que se aprehenden tales cuestiones, ¿hay algo más que sea exclusivo de la interpretación constitucional y que no sea solamente una aplicación del criterio general de razonamiento interpretativo al contenido de las Constituciones de países específicos?

Esto revive la duda acerca de la posibilidad de una teoría general del derecho constitucional, pero esta vez enfocada a los temas de interpretación. Como explique anteriormente, considero que existe mucha verdad en la duda. No hay una teoría general de interpretación constitucional, si esto significa una teoría que sea una receta general de la manera en que la interpretación debe ser conducida y que con detalle guie al intérprete con consejos prácticos en cada paso del proceso. Hay poco más que pueda decirse, aunado a "razonar bien" o "interpretar razonablemente". Lo poco que puede hacerse es señalar los errores que tienen arraigo en los jueces por la popularidad que los mismos gozan entre abogados, jueces o escritores académicos.

\section{Fidelidad E INNOVACIÓN}

La interpretación, según se ha sugerido, vive en espacios donde se mezcla la fidelidad a lo original y la disposición a la innovación. Existe una tensión dialéctica, como algunos dicen. La razón por la que encontramos esa tensión en el 
razonamiento del derecho constitucional, es que las decisiones constitucionales son decisiones morales que tienen que estar justificadas moralmente, y las consideraciones morales que pueden ser aplicables incluyen tanto la fidelidad al derecho constitucional como es, las cuales surgen por la preocupación por la continuidad, y una actitud abierta hacia las limitaciones e injusticias que la aplicación de ese derecho puede provocar en determinados casos, lo cual exige una disposición hacia la necesidad de desarrollarlo y modificarlo.

Dos errores opuestos se presentan por este hecho. El primero es pensar que debido a que una interpretación buena puede combinar ambos elementos, la distinción entre la Constitución como es y de manera más amplia el derecho por una parte y como debe ser por la otra, es ilusoria. La interpretación constitucional, dice un argumento, establece el significado de la Constitución. Esto es, no tienen sentido hablar del contenido de la Constitución excepto cuando esto sea determinado por un proceso de interpretación. Puesto que la interpretación mezcla la fidelidad y la innovación, esto niega ambas nociones. Esto rompe con la distinción entre ellas, pues la fidelidad supone que el contenido de la Constitución, al cual se supone que uno debe ser fiel, puede establecerse independientemente de la interpretación y, en el mismo sentido también la innovación, puesto que ésta es identificada como una desviación de la fidelidad pura. Sin una identificación independiente de la interpretación del contenido de la Constitución, no podemos discernir entre la fidelidad y la innovación, y puesto que el contenido no puede ser identificado independientemente de la interpretación, se sigue que no existe un significado coherente de la noción de fidelidad hacia la Constitución y tampoco de la innovación constitucional.

Este argumento falla. Sugerí anteriormente que no todas las explicaciones del significado son interpretaciones. Pero no es necesario basarnos en ello para refutar el razonamiento. El hecho es que el argumento pasa por alto que la 
razón por la que la fidelidad e innovación están a menudo mezcladas es que tenemos razones para interpretar en determinadas maneras que las combinan. Pero éste no siempre es el caso. A veces tenemos razón para interpretar la Constitución en formas que simplemente dilucidan su contenido con todo y sus excesos. Tal interpretación, que llamo "una interpretación conservadora", será exitosa si es verdadera respecto del significado existente de la Constitución. No mezclará elementos en tensión. No mostrará tensiones dialécticas y establecerá el modelo por el cual podemos medir otras interpretaciones para ver si son más o menos innovadoras.

El fracaso del argumento precedente no significa, por supuesto, que no haya otros mejores. Pero no conozco otro argumento exitoso para la misma conclusión. De esto no se deduce que en cada caso podamos establecer lo que es el derecho. La evidencia puede ser incompleta. Además, el tema no es que podamos señalar la respuesta jurídica respecto a cualquier pregunta, puesto que en muchas ocasiones el derecho es indeterminado. Como resultado, cuando se interpreta la Constitución con el propósito de establecer lo que en determinado momento es, la interpretación misma mostrará que es vaga e indeterminada. Dadas todas estas ideas, sigue siendo el caso de que cuando la evidencia es accesible es posible establecer lo que el derecho es, y por lo tanto, distinguir entre interpretaciones innovadoras y conservadoras. Sospecho que una razón que lleva a la gente a suponer que es imposible interpretar el derecho para establecer su significado en cualquier momento dado sin cambiarlo a la vez, es el siguiente tipo de argumento: (a) Los tribunales siempre pueden cambiar el derecho pertinente al caso que está frente a ellos. (b) Los tribunales pueden cambiar el derecho únicamente cuando es indeterminado. (c) Se sigue que el derecho es indeterminado en todos los casos. (d) Por tanto, ninguna interpretación puede simplemente establecer lo que el derecho es sin modificarlo. El argumento es inválido, pues de la premisa de que el derecho es inde- 
terminado en todos los casos no se sigue que una interpretación no pueda simplemente describirlo sin modificarlo. Lo único que se sigue es que tal interpretación lo describirá como indeterminado. Es aún más importante, que la segunda premisa es simplemente falsa. Los tribunales pueden desarrollar el derecho aun cuando es determinado. Ellos pueden, y frecuentemente simplemente lo modifican.

Esto nos lleva al segundo error que se debe evitar, el cual de alguna manera es opuesto al primero. Algunos tal vez piensen que si existe una distinción entre una interpretación conservadora que simplemente expone el derecho tal como es, y una innovadora que lo desarrolla y cambia, entonces debe ser posible tomar cualquier interpretación y señalar dónde se expone simplemente el derecho como es y dónde inicia el desarrollo y cambio del mismo. Debe, en otras palabras, ser posible separar la descripción y los elementos innovadores en cada enunciado interpretativo. Los que piensan que lo anterior es viable se basan en el hecho de que a veces tal separación es posible. Pero esos son relativamente extraños y seguramente no se deduce de las observaciones previas que siempre es posible. Para aclarar el primer error, argumenté la posibilidad de comparar interpretaciones diferentes por su grado de novedad y de distinguir interpretaciones innovadoras de las conservadoras (podrian ser muchas, puesto que una puede proveer interpretaciones que reestablezcan el derecho tal como fue en épocas diferentes). Sin embargo, esta idea es muy diferente a la sugerencia de que en cada interpretación uno puede separar los elementos que son fieles al derecho como es de aquellos que son innovadores. Lo único que implica mi posición es que cuando pensamos en las razones que justifican una interpretación podemos distinguir aquellas que sugieren que la interpretación debe ser fiel al derecho existente, de aquellas que sugieren que deberian desarrollarlo o incluso cambiar el derecho.

Habiendo aclarado estos dos errores teóricos, podemos afrontar uno de los errores principales a los cuales están 
propensas las teorias de la interpretación constitucional. Habiendo establecido en la sección precedente que la interpretación constitucional tiene que responder a una variedad de razones, algunas a favor de la fidelidad del derecho existente, otras a favor de su desarrollo, cambio y adaptación, es natural esperar que la tarea central de una teoría de la interpretación de la Constitución deletree las proporciones adecuadas de la innovación y de la conservación en la interpretación constitucional, o que nos diga cómo determinar los balances adecuados en cada caso. Pero esta es una concepción errónea, la cual, si no es revisada, es propensa a producir muchas teorías falsas. Lo anterior, dado que se pasa por alto el hecho de que no existe una razón única para desarrollar y cambiar el derecho constitucional. Cuando dicho derecho resulta adecuado a sus tareas y a la situación del país, no hay necesidad de cambiarlo o desarrollarlo. La modificación del derecho se da cuando éste no se encuentra determinado en relación al asunto que el tribunal tiene que decidir o cuando no es adecuado. En esos casos el tribunal debe tomar nota de las razones que han hecho que el derecho tome una forma u otra. Pero dichas razones varian enormemente tanto en naturaleza como en importancia. En estas ocasiones cualquier razón moral puede figurar en las consideraciones de un tribunal constitucional. No puede haber una respuesta general a la pregunta de cuántas razones importantes de cambio pueden haber en conflicto con razones de continuidad.

Ciertamente existen algunas generalizaciones que podemos adelantar. Por ejemplo: generalmente (más no de manera universal) se da el caso de que en la medida en que sean más grandes los errores del derecho constitucional, es menos importante preservar la continuidad y es más importante el cambio. Podemos enfatizar que algunas veces es posible reconciliar la continuidad con el cambio, introduciendo cambios en el derecho que se desvian poco del mismo, especialmente en materias donde las expectativas establecidas llevan a la gente a hacer planes sobre la base del 
derecho existente. Esto es particularmente cierto en los casos en los que la necesidad de resolver una indeterminación jurídica en relación a tal o cual asunto es la única razón para desviarse del derecho existente. En tales casos, puede ser que ninguna expectativa haya sido generada, y la resolución del caso no implica afectar la estabilidad. Uno puede continuar en este camino para ofrecer más generaciones útiles. Pero esto no llevará a una respuesta general en relación a la pregunta de cuál es en las decisiones constitucionales la combinación correcta entre la innovación y preservación.

\section{CONSIDERACIONES DEL MÉRITO MORAL \\ DE LA CONSTITUCIÓN Y DEL PAPEL INSTITUCIONAL}

Hasta este momento he sostenido cuatro importantes conclusiones; primero, no hay ninguna teoria real de interpretación constitucional, en cuanto a un conjunto de principios que aplicados a una cuestión interpretativa concreta den por resultado una correcta interpretación de la directiva constitucional respectiva. Todo lo que una discusión filosófica de la interpretación puede hacer es explicar la naturaleza de la actividad interpretativa y sus parámetros principales y ayudarnos a evitar errores. Segundo, existe una manera convincente de distinguir entre la interpretación innovadora y conservadora, y a menudo entre interpretaciones más o menos innovadoras o conservadoras. Tercero, la interpretación juega un papel central en el razonamiento jurídico porque en los razonamientos juridicos la fidelidad debe ser combinada con razones de innovación. La interpretación constitucional es fundamental en la adjudicación constitucional dado que los tribunales se enfrentan a consideraciones morales en conflicto, algunas a favor de la continuidad y que velan por dar efecto a la Constitución como es en ese momento, y otras dirigidas a la necesidad de desarrollarla y mejorarla. Cuarto, no tiene sentido preguntar en general 
cual es la correcta combinación entre lo conservador y la innovación en la interpretación constitucional.

Para lograr un mayor progreso en nuestro argumento, necesitamos mirar en retrospectiva y considerar una objeción a la tercera conclusión (objeción que dice: cualquier mérito que tengan las interpretaciones innovadoras en la literatura, historia y en cualquier otra área, las interpretaciones judiciales de la Constitución deben ser puramente conservadoras). Anteriormente argumenté contra este punto de vista sobre la base de que a) los tribunales se enfrentan a problemas morales y deben tomar decisiones moralmente justificadas y b) las consideraciones morales que ellos enfrentan frecuentemente señalan no sólo las ventajas de la continuidad, sino también la conveniencia de modificar y mejorar las directivas constitucionales respectivas. Mi opositor imaginario acepta ambas premisas, pero niega que de ellas se siga la conclusión. Parece deducirse, dice esta objeción, sólo porque se ignora completamente la importancia de las consideraciones institucionales en las decisiones jurídicas. Más allá de las consideraciones morales que adelanté, tenemos la doctrina del papel que desempeñan los tribunales, según la cual el trabajo de los tribunales es aplicar el derecho tal cual es. ${ }^{25}$ Otros tienen la responsabilidad de mejorarlo. Por tanto, el hecho de que haya buenas razones que justifican un descontento con el derecho no es una justificación para el "activismo judicial". Este no es el papel de los tribunales. Ellos tienen un trabajo que hacer y se deben dedicar a hacerlo y nada más.

El valor de esta objeción se encuentra en que nos recuerda la importancia de las consideraciones institucionales que justifican las acciones politicas y jurídicas. La objeción se basa en la doctrina de división del trabajo entre los órganos de gobierno. Pero detrás de esto existen consideraciones adicionales y complejas del diseño institucional, refe-

25 Podemos imaginar un opositor más moderado que permita a los tribunales realizar funciones creativas en determinadas circunstancias. Utilizo la posición extrema como un medio para explicar mi argumento. 
rentes a las ventajas de realizar una tarea $\mathrm{u}$ otra $\mathrm{y}$ otras necesarias para su justificación. Los filósofos algunas veces están propensos a ignorar dichas consideraciones institucionales. Sospecho que lo que contribuye a lo anterior es el hecho de que las consideraciones institucionales no marcan a un resultado como mejor que otros. Estas consideraciones simplemente indican si el tribunal es o no el órgano adecuado para adoptar una interpretación u otra, no que es mejor para el derecho hacer esto en esta u otra forma. En otras palabras, las consideraciones institucionales no contribuyen a mostrar cuál resultado es mejor. Ellas, sin embargo, muestran qué decisión está justificada. Actúan como restricciones, aunque no sean necesariamente carentes de excepciones. ${ }^{26}$

La objeción es que mi argumento pasa por alto las restricciones institucionales y que una vez que la omisión es reparada podemos ver que los tribunales no pueden modificar el derecho. En este orden de ideas, podriamos preguntarnos ¿es éste el único papel para los tribunales? Mi argumento anterior que sostiene que los tribunales tienen que tomar decisiones y alcanzar el mejor resultado moral, puede ser demasiado simplista. Es simplista en cuanto a la cuestión de quién es el agente. Los tribunales no actúan en nombre propio. Ellos actúan como órganos de una sociedad politica, simplificando el Estado. Es el Estado quien tiene la responsabilidad de alcanzar el resultado correcto. De esto no se sigue automáticamente - esto es hacia lo que apunta la objeción institucional- que debe hacerlo a través de sus tribunales. El Estado posee otros órganos y posiblemente los tribunales deben simplemente aplicar el derecho existente y si el resultado es incorrecto, esto es, si el derecho debe ser modificado, entonces dicha modificación compete a otros órganos.

26 Una noción introducida por Robert Nozick en Anarchy, State and Utopia, Nueva York, Basic Books, 1974. Su noción es una de limitantes secundarias sin excepciones, salvo en extremis; véase $28 \mathrm{ff}$. 
¿Cómo vamos, pues, a determinar la responsabilidad de los diferentes órganos del Estado? En primera instancia, examinando la estructura de los órganos del Estado y de la división de poderes establecida en la Constitución. Pero más que esto, necesitamos examinar la solidez moral de dicha estructura. No será moralmente sólida si no es una buena manera de estar seguros que el Estado alcance el resultado correcto en cada caso. En este caso corresponde a cada órgano del Estado considerar si es moralmente correcto desviarse del derecho existente con la finalidad de conseguir un mejor resultado. Esto se debe hacer balanceando las razones de continuidad, división de poderes, etcétera. Pero la pregunta de la conveniencia del cambio no puede ser evitada. No hay necesidad de explorar aquí la estructura de tal tipo de razonamiento. La lección importante es que el problema del papel relativo de las instituciones es por sí mismo, como todos los otros problemas que hemos abordado, un problema moral y los tribunales tienen que actuar con base en consideraciones morales que se aplican también a los problemas de la división del trabajo.

El hecho interesante para efectos de nuestra inquietud es si en este Estado o en otro el papel de los tribunales incluye la responsabilidad de mejorar la Constitución, lo que se convierte en una pregunta sobre la doctrina de la interpretación constitucional válida en dicho Estado. Como mencioné anteriormente, en la mayoría de los países los problemas de interpretación en este nivel tan general tienden a estar sujetos a disputas y desacuerdos. Dado que en tales países no hay una práctica establecida del problema, en ellos no hay una directiva establecida, y no hay nada que evite que los tribunales den efecto al papel que estimen es moralmente recomendable.

$¿$ Es este el punto de vista que sugiere un límite hacia los tribunales para que apliquen sólo el derecho existente?27

27 En este punto estoy ignorando la posición que cuestiona su inteligibilidad y que sostiene que cualquiera que sean las intenciones de los tribunales no pueden sino dedicarse al desarrollo y reforma del derecho, por lo menos de vez en cuando. 
Este sería su papel si y sólo si existieran otros órganos del Estado totalmente capacitados para mejorar el derecho cuando fuera necesario. Entre más rígida sea la Constitución, es menos probable que existan tales alternativas.

$¿$ Pero el hecho de que las Constituciones sean rígidas, no muestra que existen medios inadecuados de reformarlas sino que esto nos lleva a la tesis de que es indeseable que sean reformadas en otras formas distintas a los procedimientos previstos? Lo que puede significar es que esto es lo que sus autores intentaron, pero ello no implica que sus puntos de vista sean adecuados. Este es otro debate al que sólo brevemente podemos referirnos en este espacio. Lo anterior constituye una base sólida para deslindar el desarrollo constitucional del curso de las políticas ordinarias. En la mayoria de las circunstancias resulta ventajoso resguardar la estabilidad y durabilidad de la estructura de las instituciones gubernamentales y los principios fundamentales de las presiones politicas temporales. Pero el argumento para dicho deslinde no es un argumento para hacer dificil el cambio de las directivas constitucionales. Es simplemente un argumento para sostener un proceso especial que controla el cambio. El argumento en contra de los cambios fáciles es el argumento para la estabilidad y la continuidad en el derecho constitucional. Pero este argumento tiene conclusiones complejas. Establece que los cambios radicales en la estructura de la Constitución no deben ser fáciles de realizar. Su aceptación requiere de gran publicidad, debate público extenso y un consenso sustancial y durable. No existe objeción para el desarrollo regular del derecho dentro de las estructuras existentes. Tales modificaciones no subestiman la continuidad. A la larga, tienden a aumentarla. Hasta estos momentos no he distinguido entre estabilidad en el derecho - que es la ausencia de cambio en el mismo- y la estabilidad en los efectos sociales o económi-

El argumento en este texto va más allá de dicha conclusión y establece que existen ocasiones en las que los tribunales deben dedicarse a la interpretación innovadora incluso cuando puedan evitar hacerlo. 
cos del derecho. Dado que ambos a menudo van juntos, no había necesidad de distinguirlos. Pero van juntos sólo hasta el punto en que las condiciones sociales, políticas o económicas subyacentes no cambien. Cuando lo hacen, el derecho puede tener que cambiar si es que quiere tener los mismos efectos sociales o económicos. En tales casos, las interpretaciones innovadoras que modifican el derecho evitan que éste se petrifique y que poco a poco sea menos adecuado para cumplir sus funciones y a la vez requiera de una reforma integral. Por supuesto, el efecto acumulativo de la reforma pequeña y progresiva puede implicar un cambio radical en el derecho constitucional a lo largo de los años. Pero la estabilidad es consistente con el cambio lento, con todo y su efecto acumulativo. Por tanto, otorgar rigidez a la Constitución puede estar justificado dado que asegura un debate extenso y un consenso sólido como base de los cambios constitucionales radicales. Pero ello también significa que compete a los tribunales hacerse cargo de las mejoras y ajustes constitucionales tomando en consideración las estructuras existentes. Por lo tanto, el argumento institucional en contra de la interpretación constitucional innovadora por los tribunales está equivocado.

\section{CONSIDERACIONES JURÍDICAS Y MORALES:}

EL DERECHO Y SU AUTONOMÍA

En la discusión anterior se supuso que existen dos anclas para la interpretación constitucional. Por un lado, las razones a favor de la continuidad se alinean con la interpretación conservadora. ${ }^{28}$ Por otro lado, las imperfecciones en el derecho están a favor de la interpretación innovadora que desarrollará y modificará la Constitución. Las interpretaciones conservadoras articulan o fijan el significado actual de las disposiciones constitucionales en cuestión. Esto

28 Pero recuérdese la distinción expuesta anteriormente entre continuidad en el derecho y continuidad en cuanto a sus efectos. La primera generalmente se necesita sólo cuando es necesaria para la segunda. 
significa que buscan captar el sentido que estas disposiciones tienen en la práctica constitucional actual. A los pocos días de vigencia de una Constitución esto implica el significado pretendido por sus autores, en tanto que ello fue expresado en un texto a partir de convenciones de significado y la interpretación de la época. ${ }^{29}$ Posteriormente, dicho significado será uno gradualmente recubierto por capas de decisiones interpretativas y por la manera en que las disposiciones relevantes sean entendidas en las prácticas de las instituciones jurídicas de un país y de su población. Naturalmente y así entendida la Constitución, ésta será vaga e indeterminada en muchos casos. ¿Cómo pueden afectar a las interpretaciones la subdeterminación en lo moral y lo jurídico?

La indeterminación en las disposiciones constitucionales contribuirá a la existencia de interpretaciones innovadoras. Puesto que ellas simplemente determinan lo que estaba subdeterminado, no pueden ir en contra de la estabilidad. Cualesquiera que sean las razones morales viables para mejorar las disposiciones constitucionales respectivas, pueden tener un efecto dado. Algunas veces, sin embargo, habrá indeterminación tanto en el derecho como en la moralidad. Pero, el problema debe ser decidido y la posición constitucional debe ser asentada ¿Cómo debe proceder el tribunal entonces?

Una distinción establecida en la sección III es relevante en estos momentos. En tal sección distinguí entre razones de mérito, las cuales residen sobre el mérito de una Constitución y sus disposiciones, y por la otra parte, razones para reformar una Constitución o algunas de sus disposiciones, las cuales no tienen relación en lo tocante al mérito de esas disposiciones. La necesidad de un cambio que infunda un espíritu de optimismo en el futuro o a fin de ganar el apoyo o alianza de algún segmento de la población fueron ejem-

29 Esta fórmula tiene la intención de captar la conclusión de mi ensayo "Intention in Interpretation", en George, R. P. (ed.), The Autonomy of Law, Oxford, Oxford University Press, 1996, pp. 249-286. 
plos del segundo tipo de razón anotada. Cuando enfrentamos las consecuencias de la inconmensurabilidad de las razones, necesitamos distinguir entre la inconmensurabilidad de todas las razones que tienen relación con una decisión, de la inconmensurabilidad en alguna clase de razones.

Las razones de mérito que muestran que una interpretación, innovadora o no, hace que la Constitución sea mejor que sus alternativas toma lugar de honor en la interpretación constitucional. Esto no se debe a que el balance de estas razones de mérito venza a las otras razones con las que pueda estar en conflicto. Otras razones pueden válidamente vencer a las razones de mérito en diversas ocasiones. El tribunal puede, para mencionar sólo una consideración común, adoptar una interpretación inferior de la Constitución a lo que podría ser, en una interpretación alterativa a fin de apaciguar al Legislativo o un Ejecutivo hostil que pudiera tomar acción para limitar el poder de los tribunales o para comprometer su independencia. Las razones de mérito son las razones primarias porque definen la tarea de los tribunales en la interpretación constitucional: su tarea es aplicar la Constitución cuando es adecuado a su tarea y mejorarla cuando se requiere. Su éxito, y por tanto, el mérito de mantener el sistema existente de tribunales constitucionales depende de que éstos sean buenos en el desempeño de sus labores. Si a la larga los tribunales constitucionales no son tan buenos en el desempeño de sus funciones (i.e., no tan buenos como algunas alternativas pudieran serlo), entonces se tienen que asignar algunas de sus funciones a otra institución. Pero, y reitero en esto, el hecho de que las razones de mérito sean primarias no significa que sean las únicas razones constitucionales que los tribunales puedan tomar en cuenta, ni significa que sean siempre decisivas.

En la sección III se argumentó que cuando consideramos la legitimidad de la Constitución como un todo, las razones de mérito a menudo subdeterminan el fallo. Frecuentemente la Constitución que tenemos es legitima no porque sea superior a cualquier alternativa, sino porque la tenemos y 
no hay nada fundamentalmente malo en ella. Esto es, se encuentra dentro de los limites de lo moralmente permisible. De cualquier manera, sería un error considerar que de que la Constitución es legítima, se sigue el que las consideraciones de mérito no juegan algún papel en la interpretación constitucional. El hecho de que un país goce de una Constitución legitima y que haya desarrollado instituciones y prácticas que se ajustan a su Constitución, hace que muchas consideraciones de mérito sean aplicables, las que de otra manera no lo serían. Por ejemplo, dado que en las democracias una consideración mayor en la definición del alcance de la doctrina de la libertad de expresión es la importancia de la libertad para las politicas democráticas, los limites del derecho a la libertad de expresión inevitablemente dependerán en parte de los poderes del gobierno, en todas sus ramas. En términos generales podriamos decir que entre más extensos sean los poderes del gobierno, más amplio será el derecho de libre expresión.

Las razones de mérito también dependen de otros aspectos de la vida económica, social y jurídica de un país. Comparemos dos ejemplos, ambos referentes al balance apropiado entre libertad de expresión y la protección de la administración de justicia de la influencia excesiva de los medios. Primero, este balance depende de la conducta de los medios de comunicación en el país. Cuando el buen sentido común prevalece en la práctica, la libertad de prensa puede y deber ser más amplia que cuando la conducta de los medios no se interesa por la necesidad de proteger la administración de justicia de su influencia. Segundo, el balance también depende de si los juicios y otros procedimientos legales se originan ante jurados o ante un comité de jueces profesionales sin miembros del jurado. En el segundo ejemplo, la doctrina de la libertad de expresión es afectada por razones de mérito que dependen de otro aspecto de la Constitución; en el primer ejemplo, se encuentra afectada por prácticas sociales que no están consagradas por el derecho. En ambos casos, las razones de mérito pre- 
sentan un peso considerable aunque la Constitución, cuyas disposiciones se encuentren en litigio, no sea la única opción moralmente buena, sino simplemente una Constitución moralmente permitida legitimada por la práctica.

Una vez dicho lo anterior, debo agregar que mientras las razones de mérito son esenciales para la adjudicación constitucional, éstas generalmente serán inconmensurables; reprobarán al pretender determinar cuál disposición constitucional es mejor. Como fue adelantado antes, esto no significa que no habrá razones sólidas para establecer que los tribunales deben preferir una interpretación sobre otras. Sin embargo, estas razones están particularmente limitadas en el tiempo y en relación con el agente. Esto es, pueden ser razones aplicables en un momento particular, pero caen en desuso bastante rápido, y pueden ser razones para que los tribunales interpreten la Constitución en un sentido u otro, sin ser razones para que otras personas hagan lo mismo. $\mathrm{Mi}$ ejemplo sobre la forma en que el alcance de la libertad de expresión depende de qué tan conscientes son los medios de comunicación sobre la necesidad de proteger la administración de justicia, muestra el punto común de que la relatividad temporal de las razones para una interpretación constitucional afecta tanto a las razones de mérito como a otras. La forma en la que las razones de no-mérito pueden ser relativas al agente de la interpretación se muestra a través del ejemplo de la preferencia de una interpretación que no provocará alguna acción del Legislativo contra los tribunales. Supongamos que un individuo en sus negociaciones con una agencia se basa en la interpretación que si fuese adoptada por los tribunales, ofendería al Legislativo. El Ejecutivo y sus agencias no pueden legítimamente abstenerse de aceptar la validez de la interpretación debido a tales consideraciones. El supuesto es que sólo los tribunales están en desacuerdo con el Legislativo. Los órganos del Ejecutivo deben, por tanto, adoptar la interpretación apoyada por razones de mérito. Desafortunadamente, si se rehúsan a hacerlo, el individuo no podrá obtener una ayuda por parte de 
los tribunales, los cuáles correctamente estarán limitados para adoptar la "mejor" interpretación.

Puede decirse mucho más sobre el papel relativo del mérito y otras consideraciones. Pero debemos regresar al tema de la inconmensurabilidad. Permítanme resumir los puntos adelantados hasta el momento: a) las razones morales motivan todas las decisiones interpretativas, tanto las conservadoras como las innovadoras; b) las consideraciones de mérito pueden justificar una interpretación innovadora incluso cuando una interpretación conservada es posible, esto es, incluso cuando el tema se encuentra determinado por la Constitución, tal y como está en esos momentos. Éste sería el caso cuando la necesidad de mejorar el derecho es mayor que la necesidad de continuidad, y cuando exista una interpretación que mejora el derecho; c) cuando la Constitución se encuentra subdeterminada en relación al tema en cuestión, la necesidad de mejoramiento existe y no se topa con una oposición directa a partir de las consideraciones de continuidad; d) el hecho de que todo el esquema constitucional se encuentre legitimado en su conjunto por la práctica y sea permisible, esto no significa que las consideraciones de mérito estén agotadas; e) mientras que las razones de mérito son las razones primarias para las interpretaciones innovadoras, no son las únicas relevantes. Existen razones interpretativas viables que no son razones de mérito y que compiten con ellas; f) estas otras razones pueden determinar la correcta interpretación a adoptar incluso cuando tanto la Constitución como es en el momento y las razones de mérito reprueban en la resolución del problema concreto. La pregunta es: ¿de qué manera los tribunales van a decidir los casos en los que estas razones también fallan para resolver el problema y determinar el resultado del caso?

¿Por qué esto es un problema?, la acción racional es una acción con base en una razón que razonablemente se considera como no vencida. No es acción con base en una razón 
que vence a todas aquellas en conflicto con ella. ${ }^{30}$ No tenemos dificultad al escoger cuál naranja tomar de un tazón de naranjas porque no hay nada que escoger entre ellas. Por supuesto, las razones inconmensurables no son razones de igual fuerza. Pero el hecho de que ninguna razón inconmensurable venza a las otras no debiera presentar un misterio sobre cómo logramos escoger qué hacer cuando nos enfrentamos con razones inconmensurables.

La inconmensurabilidad de las razones es dominante, y no obstante estamos lejos de tener una explicación filosófica satisfactoria de todos sus aspectos, no plantea una dificultad en la explicación de cómo podemos actuar sin la creencia de que el acto que llevamos a cabo se encuentra apoyado en razones más fuertes que sus alternativas. Aún queda un problema aquí. Es un problema específico para el derecho y para otras acciones públicas. Éste no surge de la dificultad de ajustar la inconmensurabilidad de las razones con una teoría de la acción racional o de elección racional, sino de un principio de moralidad politica, principalmente del principio de responsabilidad pública de las acciones públicas. Este principio no sólo exige que los tribunales deban tomar sus decisiones con base en razones convincentes y que deban evitar razones irrelevantes, sino también que en la medida sea algo visible públicamente el que ninguna decisión irrelevante haya influido en la decisión. Este principio hace inapropiado el que los tribunales actúen tal y como la gente lo hace cuando se encuentra confrontada por la inconmensurabilidad de razones en cuanto a las opciones a las que se enfrentan. En parte, las elecciones de la gente no son exigidas por razón alguna. Éstas muestran disposiciones y gustos que se tienen, que pueden o no ser importantes en sus vidas, pero en esencia son no-racionales. Es importante que las instituciones para el público no decidan de acuerdo a explicaciones que giran en torno a disposiciones no-racionales o gustos de la gente que osten-

30 En este punto me baso en mi análisis expuesto en "Incommensurability and Agency". 
ta el puesto público respectivo. Las instituciones públicas deben desarrollar o adoptar mecanismos de distanciamiento en los que pueden confiar para resolver problemas de una manera que sea independiente de los gustos personales de los jueces o de otros funcionarios involucrados.

La necesidad de tal distanciamiento es una de las razones por las que muchos jueces continúan argumentando que en ningún punto ellos basaron sus decisiones en cuestiones ajenas a una interpretación conservadora del derecho y que sólo existe una verdadera interpretación. Pero el derecho puede y debe otorgarles mecanismos genuinos de distanciamiento. En otro lugar he sugerido que la doctrina jurídica puede $\mathrm{y}$, de hecho, juega ese papel. ${ }^{31}$ La doctrina juridica puede ser, por supuesto, sólo aquello que la moralidad ordena. Pero, comúnmente la doctrina puede tomar vida por sí misma, desligada de consideraciones morales. Esta tendencia en el pensamiento jurídico es, con frecuencia, desprestigiada como formalismo, conceptualismo o esencialismo, y a menudo la crítica es merecida.

Pero la crítica es merecida - en derecho constitucionalsólo en los casos en los que el basarse en un razonamiento jurídico formal previene el que un tribunal adopte una interpretación innovadora que pudiera mejorar la Constitución. En los casos en los que las razones para las dos o más interpretaciones plausibles son inconmensuradas, el apoyarse en el razonamiento jurídico formal se encuentra justificado; éste sirve como un mecanismo de distanciamiento.

Desde luego, no estoy argumentando que tales mecanismos de distanciamiento se encuentren siempre disponibles en el derecho. Por el contrario, he afirmado anteriormente que a menudo los mecanismos no están disponibles y que el derecho es indeterminado. Simplemente señalo la conveniencia de que se encuentren disponibles. Podemos ahora regresar por última vez al argumento expuesto anteriormente, consistente en que resulta generalmente adecuado

31 Raz, Joseph, "On the Autonomy of Legal Reasoning", Ethics in the Public Domain, 326. 
el que los tribunales adopten una interpretación innovadora incluso cuando existe una interpretación conservadora que pudieran adoptar en su lugar. Algunas doctrinas y métodos de interpretación jurídica encuadran en mi categoría de doctrinas formales, las que no están justificadas por el valor moral o cuya aplicación al caso a resolver no se encuentra justificada. Las doctrinas jurídicas formales, como he argumentado, son valiosas. Pero no deben ser utilizadas para impedir que los tribunales recurran a consideraciones morales para desarrollar y mejorar el derecho. Ellas deben traerse a colación una vez que los recursos morales han sido agotados, cuando los tribunales necesiten recurrir a mecanismos de distanciamiento para justificar su elección entre interpretaciones inconmensuradas.

\section{CODA: ¿'PERO ES LA MISMA CONSTITUCIÓN?}

Posiblemente esta duda aún no ha sido resuelta. Si los tribunales hacen la Constitución, ¿esto no implica que mucha gente que cree que está viviendo bajo una Constitución adoptada hace doscientos años esté equivocada? Si llevo razón en cuanto a lo sostenido, entonces la Constitución ha sido "rehecha" muchas veces, y en realidad no estamos viviendo conforme a la Constitución entonces promulgada. Debe admitirse que están equivocados tanto aquellos que no se dan cuenta que el derecho de la Constitución depende de las decisiones interpretativas de los tribunales así como del documento original que se interpreta y, también están equivocados quienes niegan que los tribunales se encuentran facultados para adoptar interpretaciones innovadoras. Pero no se trata de un error que considera que se trata de la misma Constitución. Sigue siendo la misma Constitución adoptada hace doscientos años, al igual que sucede con una persona que vive en una casa del siglo XVIII, vive en una casa construida hace doscientos años. $\mathrm{Su}$ casa ha sido reparada, mejorada y modificada en varias 
ocasiones, pero sigue siendo la misma casa, lo mismo sucede con la Constitución.

Una persona puede, por supuesto, oponerse a la redecoración de la casa o al cambio de sus ventanas, diciendo que no seria la misma. En ese sentido es cierto que una Constitución vieja no es la misma que una nueva, así como una persona vieja no es la misma que cuando era joven. La similitud en este sentido no es similitud de identidad (la persona vieja es idéntica a la persona joven que alguna vez lo fue). Es similitud en todas las propiedades intrinsecas del objeto. Algunas veces existen buenas razones para preservar no sólo el mismo objeto sino el objeto con todas sus propiedades intrínsecas intactas. En el caso de las Constituciones, tales razones son morales. Cuando ellas prevalecen, sólo una interpretación conservadora resulta apropiada. Como muchos otros autores, he señalado una serie de razones para considerar que no siempre prevalecen. El punto de la coda radica en la advertencia de que no se confunda el cambio con la pérdida de identidad y advertir sobre los falsos argumentos que se producen al respecto. Disipar los errores es todo lo que una teoría general de la Constitución puede aspirar a lograr. 